\title{
Environmentally assisted fatigue crack nucleation in Ti-6Al-2Sn-4Zr-6Mo
}

\author{
TP Chapman ${ }^{\mathrm{a}}$, RJ Chater ${ }^{\mathrm{a}}$, EA Saunders ${ }^{\mathrm{b}}$, AM Walker $^{\mathrm{c}}$, TC Lindley $^{\mathrm{a}}$, \\ D Dye $\mathrm{Da}^{\mathrm{a}, *}$ \\ ${ }^{a}$ Department of Materials, Royal School of Mines, Imperial College London, Prince Consort \\ Road, London, SW7 2BP, UK \\ ${ }^{b}$ Rolls-Royce plc., Materials - Failure Investigation, Bristol, BS34 7QE, UK \\ ${ }^{c}$ Rolls-Royce plc., Elton Road, Derby, DE24 8BJ, UK
}

\begin{abstract}
An unexplained feature was observed at the fatigue crack origin of a number of $\alpha / \beta$ titanium specimens tested at $450^{\circ} \mathrm{C}$ in the low cycle fatigue regime. The origin was discoloured blue but this was not a result of temper colouration; this feature sometimes resulted in large reductions in fatigue lives. A number of specimens were examined to determine the cause and formation mechanism of these "blue spots." This feature was associated with elevated oxygen and chloride levels and the presence of sodium. A mechanism based on hot-salt stress-corrosion cracking is proposed and the implications for service components are discussed.
\end{abstract}

Keywords: A. titanium, B. STEM, B. SIMS, C. hot corrosion, C. stress corrosion, C. oxidation

\section{Introduction}

Titanium alloys are widely used in the fan and compressor of aerospace gas turbines, owing to their good specific fatigue strength and low occurrence of intrinsic defects, such as the ceramic inclusions or gas porosity present from 5 melting that occur in many of the major industrial alloys [1,2]. Titanium alloys typically possess very good corrosion resistance in most circumstances, which makes them attractive in a variety of static applications in the aerospace and chemical process industries [3].

The prototypical titanium alloy, Ti- $6 \mathrm{Al}-4 \mathrm{~V}$, has historically seen very wide utilisation in the cooler sections of gas turbines. Of the other two main classes of alloys, near-alpha alloys such as Ti-6Al-2Sn-4Zr-2Mo-0.1Si and IMI834 ${ }^{1}$ are used in high temperature applications such as high pressure compressor discs, whilst

\footnotetext{
${ }^{*}$ Corresponding author.

Email address: david.dye@imperial.ac.uk (D Dye)

${ }^{1}$ IMI834: Ti-5.8Al-4.0Sn-3.5Zr-0.7Nb-0.5Mo-0.35Si-0.06C (wt.\%)
} 
heavily beta stabilised alloys such as Ti-5Al-5Mo-5V-3Cr are used for their very high strengths in applications such as landing gear [4]. However, recently

15 stronger and more heavily beta stabilised alloys such as Ti-6Al-2Sn-4Zr-6Mo (Ti-6246) have started to be used in elevated temperature applications such as high temperature compressor discs, by all of the major jet engine manufacturers.

The present work concerns the appearance of an initially unknown bluecoloured fatigue crack initiation feature, that has been observed in the elevated

20 temperature low cycle fatigue (LCF) testing of Ti-6246. These "blue spots" were observed on the fracture surface at the fatigue crack origin, and were found to be around $100 \mu \mathrm{m}$ in size. Blue is a so-called temper colour of titanium that can be associated with a $\mathrm{TiO}_{2}$ oxide film of similar thickness to the wavelength of visible light. However, the unusual feature did not possess a temper colour gradient,

25 but instead demonstrated a sharp colour boundary between the initiation site and succeeding fatigue crack. It was initially unclear whether the fatigue crack origins were sub-surface or surface breaking, but all of the blue spots intersected the surface. Some hypotheses held that an initially sub-surface crack oxidised to the blue colour on becoming surface breaking, for example. The areas around

30 the origin locations were also oxidised slightly during testing, to the extent typical for air exposures of the alloys concerned - at $450^{\circ} \mathrm{C}$ for $\sim 20-80 \mathrm{~h}$.

One of the original attractions of titanium alloys was that they were thought to be immune to corrosion-enhanced fatigue, but this was soon found to be an erroneous assumption [5, 6, 7]. Properly processed, titanium alloys' superior

35 fatigue performance are mostly due to a lack of intrinsic defects such as oxide inclusions, and hence a high fatigue crack initiation resistance [3]. Like many metals, $\mathrm{Ti}$ is also found to suffer enhanced plasticity in the presence of hydrogen [8], especially around crack tips, and can also suffer from hydride embrittlement $[9,10]$. Hydrogen has also been found to affect fatigue crack growth

40 rates $[11,12]$. Therefore, in certain circumstances where the protective $\mathrm{TiO}_{2}$ scale is broken down, Ti alloys can suffer from stress corrosion cracking, which has been the subject of study through to the present day $[13,14]$.

The crack origin was investigated using scanning electron microscopy and energy dispersive spectroscopy (SEM-EDX), transmission electron microscopy

45 (TEM) foils lifted out from the fatigue fracture surfaces and initiation points, and focussed ion beam milling - secondary ion mass spectrometry (FIB-SIMS). This led to a diagnosis of the root cause of the blue spot features, and therefore to an explanation as to why these features are not observed in ex-service titanium components.

\section{2. Material and Experimental Procedures}

The Ti-6Al-2Sn-4Zr-6Mo samples investigated in this work were supplied by Rolls-Royce Deutschland. A number of samples have been studied and all samples produced consistent results. Thus for clarity, only one such sample is discussed, which had the specimen ID U7-086. Bow-tie samples were electro 55 discharge machined (EDM) in distilled water from Ti-6246 plate before low cycle fatigue testing at $450{ }^{\circ} \mathrm{C}$ in laboratory air at the Mechanical Testing Operations 
Centre (MTOC), Rolls-Royce Deutschland. A maximum stress of $600 \mathrm{MPa}$ and minimum stress of $60 \mathrm{MPa}$ were used, and the sample endurance was 17,992 cycles. The gauge section of the samples was $6 \times 6 \mathrm{~mm}$, the gauge length was $30 \mathrm{~mm}$, and a trapezoidal (1 s loading, $1 \mathrm{~s}$ hold, $1 \mathrm{~s}$ unloading, $1 \mathrm{~s}$ hold; 1-1-1-1) waveform was used. The sides of the samples cut by EDM were polished whilst the others (including the crack initiation location) retained a surface ground finish from the parent plate. After testing, the fracture surfaces were cleaned in ethanol and distilled water.

65 The microstructure of the plate material consisted of coarse, elongated primary alpha laths $\left(\alpha_{p}\right)$ as well as much finer secondary alpha laths $\left(\alpha_{s}\right)$ residing within a retained beta phase matrix (Figure 1). The microstructure is optimised to provide good fracture toughness $\left(\alpha_{p}\right)$ and high strength $\left(\alpha_{s}\right)$ that can be maintained up to $\sim 500^{\circ} \mathrm{C}$. After $\beta$ and $\alpha+\beta$ forging, this microstructure can 70 be produced by fan air cooling from just below the $\beta$ transus, followed by ageing at $\sim 600^{\circ} \mathrm{C}$ to develop the fine scale secondary $\alpha$ structure, and air cooling.

[Figure 1 about here.]

The microstructure of the alloy was examined using a Zeiss Auriga field emission gun scanning electron microscope (FEG-SEM) using a $10 \mathrm{kV}$ accelerating voltage. Backscatter electron imaging (BSEI) mode and secondary electron imaging (SEI) mode was used for metallography and fractography, respectively. Compositions of the blue spot and the underlying surface defect were measured using energy dispersive X-ray spectroscopy (EDX) in the same SEM. The aperture was increased from 30 to $120 \mu \mathrm{m}$ during chemical mapping to enhance the so count rate but the accelerating voltage was maintained at $10 \mathrm{kV}$ to achieve a good compromise between high count rate and low interaction volume.

Transmission electron microscopy (TEM) samples were produced using the focussed ion beam (FIB) lift-out technique inside a dual beam FEI Helios NanoLab 600 using a $30 \mathrm{kV}$ primary $\mathrm{Ga}^{+}$beam. To protect the area of in85 terest, the gas injection system was used to deposit a platinum-containing ${ }^{2}$ protective layer. Samples were thinned to $\sim 180 \mathrm{~nm}$. TEM-based EDX on the blue spot layer and underlying microstructure was carried out using a JEOL 2000FX TEM with an accelerating voltage of $200 \mathrm{kV}$. Scanning transmission electron microscopy (STEM) - based EDX was conducted using a JEOL JEM-

$90 \quad 2100 \mathrm{~F}$ TEM/ STEM, again with a $200 \mathrm{kV}$ accelerating voltage. The microscope was equipped with an Oxford Instruments X-Max $80 \mathrm{~mm}^{2}$ silicon drift detector for chemical analysis.

Focussed ion beam-secondary ion mass spectrometry (FIB-SIMS) dynamic depth profiling experiments were performed using the FEI FIB200-SIMS ion

95 microscope. The FIB-SIMS instrument used was an FEI FIB200 workstation with two electric quadrupole-based, charged particle filters that can be polarised to select and analyse either positive or negative secondary ions on a mass-tocharge ratio basis. Sputtered ions were produced by a gallium liquid metal ion

${ }^{2}\left(\mathrm{C}_{9} \mathrm{H}_{16} \mathrm{Pt}\right)$ 
source with gallium ion energy chosen to be $30 \mathrm{keV}$. The working distance for the gallium beam was $17 \mathrm{~mm}$. Of the two SIMS detectors, one was an FEI SIMS detector and the second, newer detector was a Hiden EQS1000 system. The FIB-SIMS system was operated so that positive ions were detected by the FEI SIMS detector and simultaneously the negative ions generated were detected by the Hiden SIMS detector in concentration depth profiling mode [15].

Prior to any recorded FIB-SIMS compositional analyses, all the sites selected were sputter cleaned in situ using the FIB-SIMS primary gallium ion beam at a high current of $20 \mathrm{nA}$. Following this, analysis was undertaken by sputtering within rectangular craters $2 \times 50 \mu^{2}$ in size, within the sputter cleaned area. The depth of each of the craters was at least $1 \mu \mathrm{m}$, achieved after sputtering for a few minutes with a $3 \mathrm{nA}$ gallium ion beam. Craters of this size were chosen in order to sample bulk material from a representative portion of the two phase material. Two sets of rectangular craters were milled into the specimen gauge length. The craters were positioned down the specimen gauge length with the long side of the rectangular crater parallel to the fracture edge. The first set of 115 craters were placed directly beneath the blue spot with the second set at least $1 \mathrm{~mm}$ away from it. Each set of measurements included test analyses on a single crystal silicon wafer so as to consider the residual gases in the vacuum system. A schematic illustration of the experiment set-up is given in Figure 2.

[Figure 2 about here.]

\section{Results}

\subsection{Fracture surface examination}

The light optical micrograph (LOM) in Figure 3 demonstrates discolouration at the fatigue crack origin corresponding to the blue spot. The blue colour appeared quite uniform across the feature and did not show a gradual colour change with crack length. Furthermore, the boundary or outline of the blue spot was observed to be very distinct and sharp. High temperature exposure of titanium in air often results in blue/purple discolouration of the alloy surface by temper colouration. The perceived colour is a product of the thickness of the resulting $\mathrm{TiO}_{2}$ oxide film and its optical interaction with visible light via thin film interference. In the case of a growing fatigue crack and consequent discolouration of the fracture surface, thickness of the $\mathrm{TiO}_{2}$ layer will be at a maximum at the origin and will gradually decrease with crack length. Therefore colour shows a progressive change across the fracture surface before final failure. Considering this, it is not believed that the blue spot has formed as a result of temper colouration.

[Figure 3 about here.]

By comparing the LOM to the secondary electron image (SEI) in Figure 3 , an apparent change in fractographic topography was seen to coincide with the edge of the blue discolouration. Again, the fractographic boundary of the 
blue spot was very well defined. This is clearly illustrated in Figure 4(a). The blue spot boundary is demonstrated by the black outline in (a), with a higher magnification representation of this region given in (b). It is postulated that an embrittling species had provided a preferential crack pathway along or across primary alpha laths or lath boundaries, of particular orientations. Further secondary electron images from within the blue spot region revealed evidence of the underlying microstructure as primary alpha lath structures on the fracture surface; Figures 4(c) and (d). Figures 4(e) and (f) show nodular corrosion product on the fracture surface close to the initiating edge. This partially obscured the exposed microstructure and indicated an environmentally assisted crack nucleation mechanism.

[Figure 4 about here.]

As the crack extends beyond the blue spot, characteristic stage I fatigue features were observed on the fracture surface. Stage I fatigue is defined as the portion of crack growth at very low stress intensities when the plastic zone at the crack tip is confined within the microstructural unit size. A zig-zag crack path is produced via shear along the single operative slip system [16]. Figure 5a(i) was taken from a region $\sim 375 \mu \mathrm{m}$ from the origin and illustrates facet formation. It also demonstrates features with dimensions comparable to primary alpha laths in the underlying microstructure. It should be noted that although evidence of microstructural features has been observed outside the blue discoloured region, they did not possess the same cleaved appearance as the primary alpha lath structures observed within the blue spot. It is inferred that any embrittling species is likely to have been confined to the blue spot region and had not diffused far beyond it. With increasing stress intensity, a transition into stage II fatigue crack growth is seen. When the microstructural unit size is comparable to the crack tip plastic zone size, a mixture of stage I and stage II type growth occurs. Figure $5 \mathrm{~b}(\mathrm{i})$ illustrates a combination of facets (stage I) and cracking associated with striated growth shown in $\mathrm{b}(\mathrm{ii}), \sim 400 \mu \mathrm{m}$ from the origin.

[Figure 5 about here.]

Approaching $900 \mu \mathrm{m}$ from the origin, extensive secondary cracking was observed; Figure 5c(i). At higher magnification, fine striations parallel to these secondary cracks can be resolved 5c(ii). At these higher stress intensities, the plastic zone will extend over many grains and crack growth will occur via the action of two slip systems [16]. A local deviation in crack growth direction was observed at the arrows shown in Figure 5c(ii); this may be accounted for by the operation of duplex slip, consistent with stage II fatigue cracking. Finally, at very large $\Delta \mathrm{K}$ when the crack was $>5 \mathrm{~mm}$ ) in length, the remaining ligament of metal was no longer able to support the effective load experienced at the crack tip, and thus final failure occurred by ductile microvoid coalescence.

To determine the presence of a possible compositional variance at the origin, SEM-based EDX maps were acquired. Qualitative chemical maps of the crack origin are given in Figure 6 where bright pixels correspond to higher 
counts/intensity. After comparing the oxygen $(\mathrm{K} \alpha)$ map with the optical micrograph adjacent, it became clear that the blue spot was associated with elevated oxygen levels. This is mirrored by a corresponding reduction in the titanium $(\mathrm{K} \alpha)$ map. The blue spot geometry exposed in the oxygen and titanium maps closely matched that of the optical micrograph. The boundaries were sharp (not blurred), thus indicating that the observed change in oxygen concentration was sudden. An apparent local $\mathrm{Cl}$ enhancement was also observed at the origin, however the elevation was much less extreme and the boundary more diffuse.

[Figure 6 about here.]

A limiting feature of SEM based-EDX is the poor spatial resolution, resulting from a large interaction volume. This is dependent on atomic number, $Z$, but is often quoted as being up to $5 \mu \mathrm{m}$ [17]. Improved spatial resolution can be achieved by preparing very thin specimens $(\sim 150 \mathrm{~nm})$ for analysis inside a transmission electron microscope (TEM). With such thin samples, scattering within the depth of the specimen cannot occur, however the electron beam can still generate X-rays from beyond the probe focus spot and so spatial resolution is a function of foil thickness. Thus, to quantify composition near the surface, 200 two TEM foils were lifted from the fracture surface using the FIB lift-out technique; (1) inside the blue spot, Figure 7(a), and (2) from an area of stage I fatigue growth. Initially, quantitative chemical data was extracted using TEMbased point EDX analysis. Even at low magnifications a surface layer was seen to reside along the fracture surface, directly beneath the platinum layer, Figure 7(b). Chemical analysis measurements were taken at a number of positions within this layer (1-4) and compared to measurements taken from primary alpha laths (5-6). Locations of the point spectra are shown in Figure 7(b) with data given in Table 1 . The average atomic composition of the layer, as taken from spectra 1-4, was calculated as $29 \%$ titanium to $65 \%$ oxygen, plus trace elements. This approximate 1:2 atomic ratio suggested that the composition of the layer was $\mathrm{TiO}_{2}$. By contrast, chemical data measured from the primary alpha laths provided evidence for only trace amounts of oxygen. The presence of chloride had previously been implied by the faint halo of increased $\mathrm{Cl}$ intensity seen at the blue spot origin in Figure 6(d). Although very low, concentrations of $\mathrm{Cl}$ 215 were again consistently detected within the four locations along the oxide layer, but not from elsewhere in the foil.

[Figure 7 about here.]

[Table 1 about here.]

High magnification STEM-EDX mapping clearly illustrates these findings 220 (Figure 8). Dark field STEM images showed the varying contrasts generated by the protective platinum layer, the titanium alloy matrix and the oxide layer (DF-STEM). The white-dashed square demonstrates the mapping area, enlarged in the adjacent image. The oxygen map confirmed a $200 \mathrm{~nm}$ thick oxide scale with elevated oxygen counts throughout this region. As with the SEM-EDX 

reduction in titanium intensity ( $\mathrm{Ti} \mathrm{K} \alpha$ ), supporting the hypothesis that the composition of the blue spot is $\mathrm{TiO}_{2}$. Additionally, $\mathrm{Cl}$ was identified once more. On initial observation, it appeared as though $\mathrm{Cl}$ was also present in the platinum layer. However, although $\mathrm{Cl}$ concentrations are low and on the limit of 230 instrument sensitivity, this unusual result is likely to be an artefact attributed to an insufficient energy resolution and mis-indexing of the platinum $\mathrm{M}_{I I I}$ edge energy $(2.65 \mathrm{keV})$ in place of the measured chlorine $\mathrm{K} \alpha$ peak $(2.62 \mathrm{keV})$; see plot in Figure 8. Otherwise, the $\mathrm{Cl} \mathrm{K} \alpha$ map clearly demonstrates chloride residing near the base of the oxide layer and thus provides convincing data to 235 suggest that both oxygen and chloride are associated with blue spot formation. A second foil was also taken from a region beyond the blue spot to act as a comparison. In this instance, the oxide layer measured only $30 \mathrm{~nm}$ in thickness and there was no evidence to suggest chloride was present elsewhere on the fracture surface. A number of positions along the fracture surface were analysed mapping has shown that the oxide thickness within the blue spot is larger by approximately one order of magnitude, compared to elsewhere on the fracture surface. This sudden step change in thickness gives further confidence in the hypothesis that the blue spot is not formed simply by the high temperature 245 oxidation of titanium.

[Figure 8 about here.]

\subsection{Specimen gauge surface examination}

Thorough examination of the fracture surface was followed by inspection of the specimen gauge surface. Figure 9 shows a semi-elliptical feature on the gauge 250 surface directly beneath the blue spot, appearing to link the fracture surface to the gauge surface. This adjacent feature was not observed centrally beneath the blue spot but was positioned toward the blue spot boundary (Figure 9(a)). Both the blue spot and connected gauge surface feature were observed as a pair on both halves of the fracture surface. A similar feature was not observed at any other location along the fracture/gauge surface edge.

[Figure 9 about here.]

When viewed at higher magnification in SEI mode, Figure 9(b), the different surface appearance of the defect became clear. Non-contact interferometry was used to further characterise the surface of the defect. Initial results from surface maps and profilometry showed the defect to be surface negative, with a maximum depth of $\sim 3 \mu \mathrm{m}$. Considering the concave form of the defect, and the association of oxygen and chloride on the fracture surface, a hypothesis involving corrosion attack may be inferred. General corrosion and pitting are often accompanied by surface roughening, so, to highlight the roughness component, 265 a high pass fast Fourier transform (FFT) algorithm was applied to the data. The combination of the surface map and profile given in Figure 10 (right column) demonstrated the locally enhanced surface roughness, presumably from corrosion product build-up. 
[Figure 10 about here.]

Further EDX analysis was then conducted on the gauge surface. As with the blue spot, qualitative chemical mapping (Figure 11) demonstrated highly elevated oxygen counts within the surface feature, accompanied by a corresponding titanium reduction. Again, a more diffuse chloride enhancement was also observed. Semi-quantitative point analyses were also acquired, which are presented in Table 2. Spectra 1-3 were measured from within the feature and suggested the composition of the adjacent surface layer was $\mathrm{TiO}_{2}$. Up to a single atomic percent of $\mathrm{Cl}$ was also detected from the same positions, along with low levels of sodium. Unlike the subsurface material analysed in the TEM, the exterior surface of the specimen was uniformly exposed to the high temperature environment for the duration of the test. Therefore the gauge length will have undergone high temperature oxidation, which is demonstrated by the values given from spectra 4-6. However, it could be significant that although exposed for the same length of time, much higher concentrations of oxygen are detected within the surface feature compared to surrounding regions (along with some chloride). This is illustrated in Figure 11 and Table 2.

[Figure 11 about here.]

[Table 2 about here.]

FIB-SIMS dynamic depth profiling was employed in order to analyse bulk, near surface material, as well as to confirm that the chemical species measured were not from post test contamination. The sputter cleaning method described in Section 2 applied a primary ion dose density (PIDD) of $\sim 5 \times 10^{17} \mathrm{Ga}^{+}$ions per $\mathrm{cm}^{2}$ to the selected region. Each surface titanium atom was bombarded $>100$ times, ensuring none of the surface material remained in the original, uncleaned, condition. Figure 12(a) shows the surface feature beneath (and adjacent to) the blue spot on the gauge surface. Referring back to Figure 9(b) the concave profile of this adjacent feature was measured to extend $\sim 20 \mu \mathrm{m}$ down from the fracture edge. The trenches used to produce the plots given in Figure 12(c) and (d) are illustrated in Figure 12(b). Each data point in the graphs correspond to data extracted from a single $2 \times 50 \times 1 \mu^{3}$ volume. In this case, each data point is an average of the final 5 measurements at a depth approaching $1 \mu \mathrm{m}$.

[Figure 12 about here.]

Figure 12(c) and (d) show the chemical profiles for ${ }^{16} \mathrm{O}^{-},{ }^{35} \mathrm{Cl}^{-}$and ${ }^{23} \mathrm{Na}^{+}$ions directly beneath the blue spot (set 1) compared to a datum region (set 2); refer to Figure 2 for a schematic representation of the experimental procedure. It was observed for data set 1 that both ${ }^{16} \mathrm{O}^{-}$and ${ }^{35} \mathrm{Cl}^{-}$species demonstrated elevated counts within the $20 \mu \mathrm{m}$ corresponding to the surface feature pit, and returned to baseline levels thereafter. The profiles of the oxygen and chloride appeared synchronised. Considering the results from both STEM-EDX and SIMS, it is clear that the presence of chloride is not a result of post test contamination. To 

the base of the blue spot oxide layer and chloride was again measured via SIMS depth profiling, after undertaking the initial in situ sputter clean procedure.

In the SIMS community, it is widely acknowledged that ambient oxygen can enhance positive secondary ion yield $[18,19]$. Considering the data from Figure

315 12(c) it was important to account for the increased oxygen levels within the initial $20 \mu \mathrm{m}$ before analysing ${ }^{23} \mathrm{Na}^{+}$data. The sodium profile illustrated in Figure $12(\mathrm{~d})$ is therefore normalised to the equivalent oxygen data to provide a ${ }^{23} \mathrm{Na}^{+} /{ }^{16} \mathrm{O}^{-}$ratio. Evaluating the sodium profile as a ratio to oxygen ensures that the trend observed is independent of the local oxygen concentration. After 320 studying Figure $12(\mathrm{~d})$ there was also a clear elevation in the ${ }^{23} \mathrm{Na}^{+} /{ }^{16} \mathrm{O}^{-}$profile within the same $20 \mu \mathrm{m}$, as shown in Figure 12(d); this was not synchronised with the chloride (and oxygen) but has been consistently demonstrated in this way across a number of samples. Again, upon exiting the first $20 \mu \mathrm{m}$ sodium counts returned to baseline. When this was compared to the second data set it was apparent that the set 2 profiles did not deviate from the baseline measurement, even in the first $20 \mu \mathrm{m}$. This therefore demonstrated that the elevation in counts seen in the set 1 data was likely to be an effect of its proximity to the blue spot on the fracture surface and/or the linking feature on the gauge surface, perpendicular to the fracture plane.

\section{Discussion}

\subsection{Summary of main observations in context}

The uniformity of colour and well-defined outline of the blue spot led to the conclusion that formation of this feature was not a result of temper colouration. A study from the 1950 s previously examined the cracking mechanism of gas turbine fan blades manufactured from Ti-8Al-1Mo-1V [20]. In one case, the subcritical crack growth area was described to be flat and containing a number of blue discoloured semi-elliptical zones. These observations are consistent with the appearance of the blue spot described in the present study. The same authors were able to reproduce the discoloured features by deposition of salt

340 slurry on to a four-point bend loaded specimen. They concluded the initial subcritical crack growth region in one of the fan blades to have initiated from salt in a fingerprint, but later to transition to a mechanism of fatigue crack growth [20]. Other studies discuss similar findings of blue discoloured fracture surfaces. These have been detected during post failure fractographic inspection of salt coated specimens under load [21, 22].

As part of initial analysis of the specimens in the present study, both halves of the fracture surface were examined in detail. It was found that the fractographic details on opposing sides matched closely. This was seen particularly clearly within the blue spot region where evidence of underlying microstruc350 ture was seen as primary alpha laths on both sides of the fracture surface. Similar findings are quoted in papers discussing hydrogen embrittlement mechanisms. Some authors attribute the apparent symmetry to decohesion along 
$\alpha-\beta$ interfaces, based on arguments suggesting hydrogen to segregate at these regions $[23,24,25]$. Other authors discuss possible combinations of mechanisms for crack propagation, including that of cleavage [26, 27]. It is suggested that transgranular cleavage through the $\alpha$-phase platelets could result in the mirrorlike appearance of these features on opposing sides of the fracture surface.

An embrittlement mechanism, possibly involving hydrogen, was inferred from the appearance of the cleaved primary lath structures on the fracture surface. In Figures 4(e) and (f) evidence of corrosion product on the fracture surface was demonstrated within the blue spot, and along with the pit-like profile on the adjacent surface (Figure 10), gave further evidence toward corrosive attack. Additionally, chloride has been observed within both the blue spot and the adjacent feature, with sodium detected within the pit-like feature via SIMS analysis. Rideout et al described a series of tests involving various polished titanium alloy specimens in 4-point bend, with $\mathrm{NaCl}$ deposited and loaded to $85 \%$ of yield in a $350^{\circ} \mathrm{C}$ air atmosphere [28]. Cracks forming from $\mathrm{NaCl}$ exposure displayed evidence of corrosive attack on the fractured surfaces and were found to contain chloride down the length of the crack, whereas sodium was 370 only detected at the crack mouth. This is consistent with the present study. They proposed that pyrohydrolysis of the salt produced a halogen acid, which was able to penetrate the oxide film and promote hydrogen embrittlement [28]. Other authors provide evidence of chloride detection $[22,29]$ and support the theory of $\mathrm{HCl}$ formation [5].

\subsection{Mechanism}

Considering the data obtained from postmortem examination of the test specimen, a hot-salt stress corrosion cracking (HSSCC) mechanism is proposed as the method by which blue spot formation occurred. It is suggested that sodium chloride was deposited onto the specimen prior to testing, due to inadequate handling / cleaning controls. HSSCC requires a number of pre-cursors for the mechanism to initiate; (1) a salt deposit, (2) the availability of water molecules, (3) temperatures exceeding $\sim 300^{\circ} \mathrm{C}$, and (4) a surface tensile stress (residual or applied) [6]. All the aforementioned conditions were met during LCF testing of this group of specimens, thus the following reactions are suggested. Reference is made to Figure 13, that schematically illustrates the mechanism.

[Figure 13 about here.]

At ambient temperature (prior to starting the test), a thin passive oxide layer will exist across the surface of the specimen. The $\mathrm{NaCl}_{(s)}$ is deposited onto this surface film. During low cycle fatigue testing, specimens were exposed 390 to temperatures in the range of $400-500{ }^{\circ} \mathrm{C}$. Under such temperatures, titanium will react with oxygen in the static air environment. Titanium oxide is known to be an anion deficient scale, with oxygen ions acting as the mobile species which can diffuse inward through the oxide layer and react with the base alloy at the metal/oxide interface [3, 30]. Growth of the oxide scale is into the base alloy [31]. The surface of the specimen will now be coated with a uniform oxide layer 
$<100 \mathrm{~nm}$ thick. It is then proposed that the sodium chloride salt deposit reacts with the surface titanium oxide scale (in the presence of moisture) to produce sodium titanate and gaseous hydrogen chloride. Most studies do not explicitly state where the water comes from, though it is commonly considered either to be from moisture in the atmosphere, or fluid inclusions in the salt [6], or adsorbed onto the titanium surface [32]. Only small quantities are required [33]. Although no direct evidence was found from our results, traces of sodium titanate have been determined from X-ray diffraction experiments in previous studies [5] and production of $\mathrm{Na}_{2} \mathrm{TiO}_{3}$ (via reaction 1 ) has been found to be thermodynamically 405 favourable [34].

$$
\mathrm{TiO}_{2(\mathrm{~s})}+2 \mathrm{NaCl}_{(\mathrm{s})}+\mathrm{H}_{2} \mathrm{O}_{(\mathrm{g})} \longrightarrow \mathrm{Na}_{2} \mathrm{TiO}_{3(\mathrm{~s})}+2 \mathrm{HCl}_{(\mathrm{g})}
$$

Reaction 1 is thought to occur at specific sites beneath the salt deposit. It is not fully understood but is considered to be dependent upon local concentration/chemistry of the contaminant, defects in the oxide scale and possibly underlying slip systems and/or orientations of surface primary $\alpha$. In any case, reaction 1 consumes $\mathrm{TiO}_{2}$, disrupts the thin oxide scale and exposes the underlying titanium base alloy. Titanium is a very reactive metal and is normally considered to be resistant to stress corrosion cracking. In oxygen or water containing environments titanium forms a passive and self-healing surface oxide film [35]. However, in the $\mathrm{HCl}$-rich environment under the salt deposit, re-passivation 415 by regeneration of the oxide is inhibited. In effect, the metal is shielded from oxygen by a stronger oxidiser - $\mathrm{Cl}$. Under fatigue loading conditions such as those experienced here $\left(\sigma_{\max }=600 \mathrm{MPa}\right)$, surface tensile stresses promote slip activity that expose bare metal at the crack tip. This bare metal is then not re-passivated, leaving it susceptible to corrosive attack. It is suggested that the ${ }_{420}$ highly reactive bare metal reacts with the gaseous hydrogen chloride, dissolving the base alloy and allowing a narrow channel to advance into the metal. Such channels have been observed in the earliest stages of hot salt attack [36].

$$
\mathrm{Ti}_{(\mathrm{s})}+4 \mathrm{HCl}_{(\mathrm{g})} \longrightarrow \mathrm{TiCl}_{4(\mathrm{~g})}+4 \mathrm{H}
$$

The result of reaction 2 is the generation of monatomic hydrogen and titanium chlorides. One of the titanium chlorides $-\mathrm{TiCl}_{2}$ - is solid in the $400-500{ }^{\circ} \mathrm{C}$ 425 range, whereas $\mathrm{TiCl}_{4}$ is gaseous and volatile. $\mathrm{TiCl}_{3}$ is a solid at $400^{\circ} \mathrm{C}$ and is unstable above $425^{\circ} \mathrm{C}$, decomposing into the other two chlorides [37]. The volatile $\mathrm{TiCl}_{4}$ then meets water molecules under or at the deposit, generating $\mathrm{TiO}_{2}$ and fresh $\mathrm{HCl}$ via reaction 3.

$$
\mathrm{TiCl}_{4(\mathrm{~g})}+2 \mathrm{H}_{2} \mathrm{O}_{(\mathrm{g})} \longrightarrow \mathrm{TiO}_{2(\mathrm{~s})}+4 \mathrm{HCl}_{(\mathrm{g})}
$$

This continues the supply of $\mathrm{HCl}$ to the reaction site and thus of hydrogen into the titanium. During cyclic loading, shear along preferential crystallographic planes will occur on the positive tensile loading portion of the cycle, promoting formation of a slip step and access to newly generated bare metal [38]. Blackburn and Williams agree with the theory of formation of a large slip step for 
crack nucleation [27]. Gaseous hydrogen chloride continues to react with newly exposed metal, extending channels deeper into the base alloy until the supply of $\mathrm{HCl}$ is exhausted. The deduction is that nascent hydrogen is adsorbed onto the exposed titanium at the base of the channel from where it diffuses into the bulk metal. It is widely accepted that the hydrogen concentrates just ahead of the channel, in a region of high hydrostatic stress when under load [39, 40, 33, 41].

440 Hydrogen would be expected, for instance, to concentrate at dislocation cores and other plasticity related defects that increase the volume of interstitial sites. This theory is consistent with findings from previous work that show evidence of microporosity at the tip of an advancing crack, at stress intensities well below the critical value for the bulk alloy [42]. Furthermore, the porosity is said to 445 reside at the $\alpha / \beta$ interface which has been proposed as the region of highest hydrogen concentration $[24,43]$. The result of localised hydrogen segregation is embrittlement of a narrow region around the tip of the reaction channel where there is now likely to be a stress concentration. At some point after load is applied, the fracture toughness of the locally embrittled zone falls below the 450 stress intensity at tip of the channel and promotes corrosion crack initiation. The previously created channels therefore act as precursors to crack initiation as they are sites providing transport of hydrogen into the metal and a stress concentration to localise it, leading to embrittlement.

Two different explanations for the embrittlement mechanism have been indicated. These are based on either a decohesion type model, or one involving hydrogen enhanced plasticity [8]. Many authors have previously hypothesised about intergranular separation of $\alpha / \beta$ interfaces as a result of weakened lattice bonds due to hydrogen interstitals [30, 25, 23]. However, considering the transgranular appearance of the fracture surface in the blue spot region, it is ${ }_{40}$ speculated that hydrogen enhanced localised plasticity (HELP) is the mechanism of embrittlement in this case [8]. In either instance, embrittlement enables crack advance from the channel root at stress intensities below that required for cracking bulk, uncharged material. It is proposed that crack advance occurs by transgranular cleavage of the alpha phase [27] along preferred slip planes [8].

The damaged oxide scale allows contact between chemical species formed in the crack and the external environment, leading to the continued loop of reactions 2 and 3 . It is hypothesised that gaseous titanium chlorides move up toward the crack mouth to be hydrolysed. Hydrolysis of the gaseous titanium chlorides produces reaction products of solid titanium dioxide and a self-sustaining cycle 470 of gaseous hydrogen chloride. This is consistent with previous findings that claim a regenerating cycle of chloride $[5,22]$. Reaction 3 occurs at the crack mouth, thus it is proposed that $\mathrm{TiO}_{2}$ is deposited at the crack mouth and blocks contact between species within the cracked channel and the hygroscopic salt deposit. Previous authors have concluded that formation of $\mathrm{TiO}_{2}$ during $\mathrm{HSSCC}$ 475 can act as "a plug" and "inhibit further generation of titanium chlorides" [22]. The present authors consider that shear at the crack tip and consequent slip dissolution promotes formation of a slip step and provides access to bare titanium for hydrogen charging, resulting in embrittlement and crack extension. Rupture of the titanium alloy substrate will certainly cause rupture of the brittle reaction 

the crack walls near the mouth, allowing further hydrolysis of titanium chlorides and a looping process between reactions 2 and 3 to proceed.

The proposed mechanism considers water, via gaseous $\mathrm{HCl}$, to be the source of hydrogen in this HSSCC mechanism, a hypothesis which is supported by

485 many from the 1960s and 70s $[6,33]$. Chloride is therefore the means by which hydrogen from water molecules is transported into the crack tip. Once the looping reactions are initiated, gaseous $\mathrm{HCl}$ is supposed to move down the crack towards the exposed titanium at the crack tip where it dissociates. A simultaneous reaction between exposed titanium and chloride ions produces the titanium chlorides and provides free electrons to reduce $\mathrm{H}^{+}$ions and allow diffusion of atomic hydrogen ahead of the crack tip.

Concentration of hydrogen at the reaction site is dependent on the balance between the competing reactions of hydrogen charging vs hydrogen diffusion. The rate of charging needs to be high enough to sufficiently embrittle the area before the hydrogen diffuses away from the highly stressed material and into the bulk. Assuming temperature, reaction rate and stress are maintained, local increases in hydrogen content will cause the fracture toughness of the hydrogen loaded region to reduce. Meyn showed that only small concentrations of hydrogen are required to cause cracking below the fracture toughness of the bulk

500 alloy [44]. Upon reaching a critical value, the stress intensity at the base of the crack will exceed the fracture toughness of the hydrogen concentrated region, allowing an increment of crack growth. Cracking stops upon contacting an area, sufficiently low in hydrogen, that no longer exceeds the fracture toughness [32]. Further hydrogen is generated ahead of the crack and upon reaching a critical value, the cycle repeats.

To the knowledge of the authors, blue spot features are not commonly observed. Ti-6Al-2Sn-4Zr-6Mo could be particularly susceptible to the HSSCC mechanism. Referring back to Figure 1, it can be seen that the microstructure consists of acicular primary alpha platelets in a continuous beta phase matrix.

510 The beta phase is known to have higher solubility for hydrogen and demonstrates a much faster rate of hydrogen diffusion than the alpha phase $[9,10]$. Materials with a continuous beta phase matrix (lamellar Ti-6246) are said to provide a "short circuit transport path" for hydrogen [25, 45]. Equiaxed Ti$6 \mathrm{Al}-4 \mathrm{~V}$ is often used at lower temperatures than lamellar Ti-6246, but to date, 515 blue spots have not been observed. The continuous beta phase in fully lamellar Ti-6246 could increase susceptibility to HSSCC by promoting efficient diffusion of hydrogen.

It must be reiterated that the blue spot observed at the fatigue crack origin is not thought to have formed as a result of temper colouration. Titanium 520 specimens subjected to high temperature fatigue are sometimes found to have progressively changing bands of colour originating at their fatigue crack origins. Such temper colour banding results from high temperature exposure of bare titanium during crack extension and formation of a thin oxide layer during growth. The precise colour observed is dependent upon time at temperature 525 and the consequent thickness of the oxide layer. Therefore, oxide thickness is 
at a maximum at the origin where exposure has been greatest, and gradually decreases to the point on the fracture surface coinciding with the transition to fast fracture. In this case however, it has been shown that the blue spot is associated with a sudden step change in oxide thickness, measuring in excess of $250 \mathrm{~nm}$ within the blue spot and less than $50 \mathrm{~nm}$ immediately adjacent to it. Furthermore, evidence from STEM-EDX mapping in Figure 8 demonstrates the presence of $\mathrm{Cl}$ within the blue spot layer.

It is postulated that upon formation of titanium chlorides in reaction 2, the solid species and some of the gaseous species are trapped during formation and deposition of $\mathrm{TiO}_{2}$ in reaction 3. This would account for the chlorine identification in the blue spot layer and is consistent with previous studies that state chloride ions would be expected to extend down the crack [33]. It is hence believed that the blue spot layer is formed via reaction 3 and is associated with the deposition and consequent rupture of the $\mathrm{TiO}_{2}$ reaction product near the mouth of the crack. Therefore, we differentiate between a temper colour and a blue spot by considering the former to result as a consequence of direct high temperature exposure of titanium over time, compared to the latter resulting as a product of the hydrolysis of titanium chlorides, produced as a by-product of the HSSCC mechanism.

\subsection{Alloying effects}

Commercially pure (unalloyed titanium) is considered to be immune to SCC, providing the oxygen content remains below a critical value [46, 47]. However, a large number of titanium-base alloys are found to be susceptible to SCC in varying degrees [28, 48]. Consequently, alloy composition is seen to have a significant effect on SCC sensitivity. Rideout et al conducted a study comparing the susceptibility of several aluminium containing alloys. They found the susceptibility of alloys to SCC increased with increasing aluminium content [28]. In other studies, workers found that $\mathrm{Al}$ was preferentially attacked by $\mathrm{NaCl}$ salts $[6,49]$. Ordering of aluminium in slowly cooled Ti-Al alloys can give rise to planar slip, which provides an additional rationale for the enhanced vulnerability of aluminium containing alloys to HSSCC compared to commercially pure titanium [27].

Tin is another alloying element in Ti-6246 and, considering its alpha-stabilising nature, has been suggested to have a similar effect to aluminium [27]. In section

5604.2 , a very streamlined version of the reactions were suggested. In fact, many other reactions are possible and several different metal-chlorides have been detected in the past $[28,49]$. Additional reactions at $450^{\circ} \mathrm{C}$ could therefore be as follows:

$$
\begin{aligned}
& \mathrm{Ti}_{(\mathrm{s})}+2 \mathrm{HCl}_{(\mathrm{g})} \longrightarrow \mathrm{TiCl}_{2(\mathrm{~s})}+2 \mathrm{H} \\
& \mathrm{Ti}_{(\mathrm{s})}+3 \mathrm{HCl}_{(\mathrm{g})} \longrightarrow \mathrm{TiCl}_{3(\mathrm{l})}+3 \mathrm{H} \\
& \mathrm{Al}_{(\mathrm{s})}+3 \mathrm{HCl}_{(\mathrm{g})} \longrightarrow \mathrm{AlCl}_{3(\mathrm{~g})}+3 \mathrm{H} \\
& \mathrm{Sn}_{(\mathrm{s})}+2 \mathrm{HCl}_{(\mathrm{g})} \longrightarrow \mathrm{SnCl}_{(\mathrm{l})}+2 \mathrm{H}
\end{aligned}
$$




$$
\mathrm{Sn}_{(\mathrm{s})}+4 \mathrm{HCl}_{(\mathrm{g})} \longrightarrow \mathrm{SnCl}_{4(\mathrm{~g})}+4 \mathrm{H}
$$

Of course, all these reactions produce atomic hydrogen and assuming all happen simultaneously may increase the rate of hydrogen charging into the

570 variations to reaction 3 are also introduced:

$$
\begin{aligned}
2 \mathrm{AlCl}_{3(\mathrm{~g})}+3 \mathrm{H}_{2} \mathrm{O}_{(\mathrm{g})} & \longrightarrow \mathrm{Al}_{2} \mathrm{O}_{3(\mathrm{~s})}+6 \mathrm{HCl}_{(\mathrm{g})} \\
\mathrm{SnCl}_{4(\mathrm{~g})}+2 \mathrm{H}_{2} \mathrm{O}_{(\mathrm{g})} & \longrightarrow \mathrm{SnO}_{2(\mathrm{~s})}+4 \mathrm{HCl}_{(\mathrm{g})}
\end{aligned}
$$

We therefore propose that the volatile gaseous metal chlorides are involved in the hydrolysis reaction, emphasising the regeneration cycle of gaseous $\mathrm{HCl}$, 575 whereas the solid titanium dichloride is likely to be the $\mathrm{Cl}$ species found in the blue spot layer. $\mathrm{TiCl}_{2}$ has been detected either along the crack or on the fracture surface in several different HSSCC studies [50, 5, 22]. It is therefore proposed that attack of alloying elements is an important aspect of the HSSCC mechanism, without which it is unlikely that sufficient hydrogen charging would occur

580 to promote hydrogen embrittlement of the base alloy and consequently lead to hot-salt assisted crack nucleation. This hypothesis is supported by Rideout et al [28], and by Chevrot [36], who laid out the thermodynamic basis.

\subsection{Transition from HSSCC to LCF crack propagation}

With infinite salt available and sufficient stress, the corrosion-assisted crack585 ing mechanism described in section 4.2 will prevail for the duration of crack propagation. It will only cease when the crack length becomes so large that the remaining ligament of metal can no longer support the applied load, and fails by fast fracture. However, in the present case there was a transition from HSSCC to low cycle fatigue crack growth. The transition was sudden and accounts for the clear optical boundary associated with the blue spot, the change in fracture mode, and the step change in oxide thickness, relating to the $\mathrm{TiO}_{2}$ reaction product in reaction 3 . This mechanism change could result from several factors, however each refers back to insufficient embrittlement.

We consider the $\mathrm{NaCl}$ deposit to have resulted from finger prints or perspiration due to inadequate cleaning of the specimen immediately prior to testing. There is therefore a finite supply of the contaminant. Gaseous $\mathrm{HCl}$ is first formed in reaction 1 . With a finite amount of $\mathrm{NaCl}$ available, the supply will soon be exhausted. Of course, the self sustaining generation of $\mathrm{HCl}$ through the looping of reactions 2 and 3 is still anticipated, however some of the titanium 600 alloy chlorides are considered to be gaseous and therefore losses can be expected. A related effect that may decrease the rate of hydrogen charging is the declining concentration of $\mathrm{HCl}$ at any given point on the hot-salt crack front as the crack area increases. This may be compounded by the notable crack branching seen in the HSSCC of titanium. In either case, production of $\mathrm{HCl}$, and therefore

monatomic hydrogen, is adversely affected. As the rate of hydrogen charging slows (relative to the rate of diffusion away from the reaction site), there will 
be a lower concentration of hydrogen after a given reaction time, reducing the extent of embrittlement ahead of the crack tip. At the point where the local concentration of hydrogen is insufficient to cause further cracking, it is proposed that the lack of crack advance will mean the $\mathrm{TiO}_{2}$ reaction product does not rupture and hence the looping reaction is stifled. No further $\mathrm{HCl}$ or hydrogen charging will occur and any hydrogen at the tip of the crack will diffuse into the bulk. Providing that applied stress is sufficient, it is expected that upon reaching the stage of insufficient embrittlement to cause stress corrosion crack-

${ }_{615}$ ing, there is a transition to fatigue crack growth, which will continue to be the mechanism of crack growth until reaching fast fracture at the end of the fatigue life. The transition will be sudden. As the crack grows in fatigue, the oxide at the mouth of the crack should rupture due to increased crack opening, but for the aforementioned reasons, the embrittlement is too low to activate the HSSCC mechanism. There is no evidence of a return to the HSSCC mechanism after the transition into fatigue crack growth.

\subsection{Effect on gas turbine components}

Salt deposits of up to $0.03 \mathrm{mg} / \mathrm{cm}^{2}$ have been measured from unfailed exservice gas turbine compressor aerofoils whilst concentrations of only $0.005 \mathrm{mg} / \mathrm{cm}^{2}$ have been found to cause HSSCC in lab specimens [51, 52]. Therefore it is accepted that enough salt to trigger HSSCC exists during flight cycles, but despite this no service failures have been determined to have occurred as a direct result of HSSCC [51]. Many authors attribute this to one of the many inconsistencies between laboratory tests and real flights. Laboratory tests are frequently ${ }_{630}$ undertaken in stagnant air environments whilst engine components operate at high rotational speeds in moving air. It is commonly proposed that the fast air streams present during real flights act to remove corrosion products thus preventing reactions leading to embrittlement $[53,34]$. Other authors disagree with this conclusion suggesting the reaction products are not gaseous, and hence do not believe high velocity gases would remove liquid/solid contaminants to prevent cracking in service [54].

Previous work undertaken on IMI 834 studied the effect of environmental pressure on the life of specimens subjected to HSSCC conditions. It was found that higher pressures significantly increased lives of specimens tested at two ${ }_{640}$ stress levels [36]. The theory proposed by Chevrot uses a concept of insufficient hydrogen charging as a consequence of pressure dependent reactions to explain engine experience. It was proposed that at the lower pressures experienced during laboratory (atmospheric) and spinning rig tests (partial vacuum), the reactions operating are those stated in section 4.2, involving pyrohydrolysis of

645 titanium alloy chlorides. However, at the higher pressures within the core of an operating gas turbine engine, reaction 3 moves away from hydrolysis and towards a reaction with oxygen:

$$
\begin{gathered}
\mathrm{TiCl}_{4(\mathrm{~g})}+\mathrm{O}_{2(\mathrm{~g})} \longrightarrow \mathrm{TiO}_{2(\mathrm{~s})}+2 \mathrm{Cl}_{2(\mathrm{~g})} \\
2 \mathrm{AlCl}_{3(\mathrm{~g})}+\frac{3}{2} \mathrm{O}_{2(\mathrm{~g})} \longrightarrow \mathrm{Al}_{2} \mathrm{O}_{3(\mathrm{~s})}+3 \mathrm{Cl}_{2(\mathrm{~g})}
\end{gathered}
$$




$$
\mathrm{SnCl}_{4(\mathrm{~g})}+\mathrm{O}_{2(\mathrm{~g})} \longrightarrow \mathrm{SnO}_{2(\mathrm{~s})}+2 \mathrm{Cl}_{2(\mathrm{~g})}
$$

650

In this case the gaseous product is diatomic chlorine, rather than hydrogen chloride, and thus the self sustaining looping reaction to produce $\mathrm{HCl}$, and therefore production of atomic hydrogen, is thought to be stifled. The consequence is an insufficient concentration of hydrogen to promote cracking at the applied stress levels. Therefore service components appear to be unaffected by finger prints and are not susceptible to HSSCC. This theory implies there is a balance between pyrohydrolysis and oxidation, that is sensitive to the relative availability of oxygen.

\section{Conclusions}

A previously unexplained "blue spot" phenomenon found at the origin of fatigue cracks in elevated temperature test specimens has been determined to be the consequence of hot salt stress corrosion cracking in the presence of small deposits of $\mathrm{NaCl}$ contamination. The following observations are made:

1. The blue coloured fatigue crack origin is associated with trace $\mathrm{Cl}$ and a $\mathrm{TiO}_{2}$ oxide scale on the order of $200 \mathrm{~nm}$ thick. In this region, the alpha plates have a cleaved appearance. These measurements were confirmed using STEM-EDX TEM foils removed by FIB milling.

2. On the adjacent surface, a shallow, rough $\mathrm{Na}$ and Cl-containing eroded region is observed by FIB-SIMS.

3. The crack origin is therefore consistent with a hypothesis of hot salt stress corrosion cracking. The mechanisms of HSSCC have been discussed in light of the results in order to clarify the extensive literature on the subject.

4. During the early stages of reaction, $\mathrm{HCl}$ formed from the $\mathrm{NaCl}$ deposit, and reacted with the titanium alloy. Hydrogen was adsorbed, embrittling the alloy and leading to cracking, e.g. via the hydrogen enhanced localised plasticity (HELP) mechanism. Titanium chloride(s) also formed, allowing the regeneration of $\mathrm{HCl}$ at the crack mouth. As the crack grew, the decreasing rate of reaction reduced the level of embrittlement, and thus the corrosion crack growth rate, until HSSCC could no longer occur at the prevailing stress, giving rise to a transition to conventional fatigue crack growth, and hence the observation of the "blue spot".

5. It is proposed that at high pressures such as are present in operational gas turbines, the titanium alloy chloride reactions proceed more readily with oxygen than with water vapour due to its greater availability, thus reducing the regeneration of $\mathrm{HCl}$. This provides a rationale for the nonobservation of HSSCC in service components.

\section{Acknowledgements}

The authors would like to thank Mahmoud Ardakani at Imperial College London for assistance provided during STEM-EDX dot mapping experiments. 
Finally we would like to thank David Rugg at Rolls-Royce Derby and many others at Rolls-Royce Dahlewitz for useful conversations. Funding from EPSRC (grants EP/H004882/1 and EP/K034332/1, plus a DTA CASE conversion $\mathrm{EP} / \mathrm{J} 500239 / 1$ for T.P.C) is acknowledged.

\section{References}

[1] A. Mitchell. Melting, casting and forging problems in titanium alloys. Mater. Sci. Eng. A, 243 (1988) 257-262.

[2] A. Mitchell. The electron beam melting and refining of titanium alloys. Mater. Sci. Eng. A, 263 (1999) 217-223.

[3] G. Lütjering, J.C. Williams. Titanium. second ed., Springer, New York, 2003.

[4] R.R. Boyer, R.D. Briggs. The use of $\beta$ titanium alloys in the aerospace industry. J. Mater. Eng. Perform., 14 (2005) 681-685.

[5] V.C. Petersen, H.B. Bomberger. The mechanism of salt attack on titanium alloys. Stress Corrosion Cracking of Titanium: ASTM Special Technical Publication, 397 (1966) 80-94.

[6] S.P. Rideout, M.R. Louthan Jr., C.L. Selby. Basic mechanisms of stresscorrosion cracking of titanium. Stress Corrosion Cracking of Titanium: ASTM Special Technical Publication, 397 (1966) 137-151.

[7] R. Duttweiler, R. Wagner, K. Antony. An investigation of stress-corrosion failures in titanium compressor components. Stress Corrosion Cracking of Titanium: ASTM Special Technical Publication, 397 (1966) 152-178.

[8] D.S. Shih, I.M. Robertson, H.K. Birnbaum. Hydrogen embrittlement of $\alpha$ titanium: in situ TEM studies. Acta Metall., 36 (1988) 111-124.

[9] E. Tal-Gutelmacher, D. Eliezer. Hydrogen-assisted degradation of titanium based alloys. Metall. Trans., 45 (2004)1594-1600.

[10] E. Tal-Gutelmacher, D. Eliezer. The hydrogen embrittlement of titaniumbased alloys. JOM, 46 (2005) 46-49.

[11] Y.S. Ding, L.W. Tsay, C. Chen. The effects of hydrogen on fatigue crack growth behaviour of Ti-6Al-4V and Ti-4.5Al-3V-2Mo-2Fe alloys. Corros. Sci., 51 (2009) 1413-1419.

[12] R. Gaddam, R. Pederson, M. Hörnqvist, M.-L. Antti. Fatigue crack growth behaviour of forged Ti-6Al-4V in gaseous hydrogen. Corros. Sci. 78 (2014) 378-383.

[13] A.L. Pilchak, A.H. Young, J.C. Williams. Stress corrosion cracking facet crystallography of Ti-8Al-1Mo-1V. Corros. Sci. 52 (2010) 3287-3296. 
[14] M.D. Pustode, V.S. Raja, N. Paulose. The stress-corrosion cracking susceptibility of near- $\alpha$ titanium alloy IMI 834 in presence of hot salt. Corros. Sci. 82 (2014) 191-196.

[15] R.J. Chater, B.A. Shollock, D.S. McPhail, A.J. Smith, G. Cooke. Differentially pumped quadrupole SIMS probe on FIB-based and two-beam microscopes Surf. Interface Anal. 46(2014) 372-374.

[16] S. Suresh. Fatigue of Materials. second ed., Cambridge University Press, 1998.

[17] D. Brandon, W.D. Kaplan. Microstructural Characterization of Materials. second ed., John Wiley and Sons, 2008.

[18] J. Kikuma, H. Imai. Yield enhancement effect of low-energy $\mathrm{O}_{2}{ }^{+}$ion bombardment in Ga focused ion beam SIMS. Surf. Interface Anal., 31 (2001) 901-904.

[19] T. Sakamoto, B. Tomiyasu, M. Owari,, Y. Nihei. Ambient oxygen effect in $\mathrm{Ga}^{+}$FIB-SIMS. Surf. Interface Anal., 22 (1994) 106-110.

[20] E. U. Lee, R. G. Mahorter,, J. D. Wacaser. Fracture of Ti-8Al-1Mo-1V alloy fan blade by stress corrosion cracking and fatigue. ASTM Special Technical Publication, 645 (1957) 128-143.

[21] M.J Donachie, Jr., W.P. Danesi, A.A. Pinkowish. Effects of salt atmosphere on crack sensitivity of commercial titanium alloys at 600 and 900F. Stress Corrosion Cracking of Titanium: ASTM Special Technical Publication, 397 (1966) 179-193.

[22] A.J. Hatch, H.W. Rosenberg, E.F. Erbin. Effects of environment on cracking in titanium alloys. Stress Corrosion Cracking of Titanium: ASTM Special Technical Publication, 397 (1966) 122-136.

[23] H.G. Nelson. A film-rupture model of hydrogen-induced, slow crack growth in acicular alpha-beta titanium. Metall. Trans. A, 7A (1976) 621-627.

[24] H. Margolin. Stress, hydrogen segregation, and fracture in $\alpha-\beta$ titanium alloys. Metall. Trans. A, 7A (1976) 1233-1235.

[25] H.G. Nelson. Aqueous chloride stress corrosion cracking of titanium - a comparison with environmental hydrogen embrittlement. NASA TM X62314, 1973.

[26] R.R. Boyer, W.F. Spurr. Characteristics of sustained-load cracking and hydrogen effects in Ti-6Al-4V. Metall. Trans. A, 9A (1978) 23-29.

[27] M.J. Blackburn, J.C. Williams. Metallurgical aspects of the stress corrosion cracking of titanium alloys. In Proceedings of Conference on Fundamental Aspects of Stress Corrosion Cracking, 1969. 
[28] S.P. Rideout, R.S. Ondrejcin, M.R. Louthan Jr. The science, technology and application of titanium alloys. Pergamon Press, 1970.

[29] R.S. Ondrejcin. Chlorine gas and fluoride ion in hot-salt stress corrosion cracking of titanium-aluminium alloys. NASA DP-1179, 1969.

[30] H.L. Logan, M.J. McBee, C.J. Bechtoldt, B.T. Sanderson, G.M. Ugiansky. Chemical and physical mechanisms of salt stress-corrosion cracking in the titanium 8-1-1 alloy. Stress Corrosion Cracking of Titanium: ASTM Special Technical Publication, 397 (1966) 215-229.

[31] N Birks. Introduction to the High Temperature Oxidation of Metals. Cambridge University Press, 2006.

[32] J.R. Myers, J.A. Hall. Hot salt stress-corrosion cracking of titanium alloys: An improved model for the mechanism. Corrosion - NACE, 33(7) (1977) $252-257$.

[33] M. Garfinkle. An electrochemical model for hot-salt stress-corrosion of titanium alloys. Metall. Trans., 4 (1973) 1677-1686.

[34] V.C. Petersen. Hot-salt stress-corrosion of titanium: a review of the problem and methods for improving the resistance of titanium. J. Metals, (1971) $40-47$.

[35] R. Schutz. Stress-corrosion cracking of titanium alloys. Stress-Corrosion Cracking: Materials Performance and Evaluation, ASM International (1992) 265-294.

[36] T. Chevrot. Pressure effects on the hot-salt stress-corrosion cracking of titanium alloys. PhD thesis, School of Industrial and Manufacturing Science, Cranfield University, 1994.

[37] L.-L. Gundersen, F. Rise, K. Undheim, J. Mèndez-Andino. e-EROS Encyclopedia of Reagents for Organic Synthesis, chapter Titanium (III) Chloride. John Wiley and Sons, Inc, New York, USA, 2007.

[38] F.P. Ford. Mechanisms of environmentally-assisted cracking. Int. J. Press. Vessel Pip., 40 (1989) 343-362.

[39] G.H. Koch, A.J. Bursle, R. Liu, E.N. Pugh. A comparison of gaseous hydrogen embrittlement, slow-strain-rate hydrogen embrittlement, and stresscorrosion cracking in Ti-8Al-1Mo-1V. Metall. Trans. A, 12A (1981) 18331843.

[40] F. Mignot, V. Doquet, C. Sarrazin-Baudoux. Contributions of internal hydrogen and room-temperature creep to the abnormal fatigue cracking of Ti6246 at high $K_{\max }$. Mater. Sci. Eng. A, 380 (2004) 308-319.

[41] E.L. Kochka, V.C. Petersen. The salt corrosion of titanium alloys at elevated temperatures. Crucible Steel Company of America, 1961. 
[42] D.N. Williams. Subcritical crack growth under sustained load. Metall. Trans., 5 (1974) 2351-2358.

[43] T.L. MacKay. Effect of stress on microsegregation of hydrogen at elevated temperatures in titanium and Ti-8Al-1Mo-1V. Metall. Trans., 2 (1971) $2299-2302$.

[44] D.A. Meyn. Effect of hydrogen on fracture and inert-environment sustained load cracking resistance of $\alpha-\beta$ titanium alloys. Metall. Trans., 5 (1974) 2405-2414.

[45] D.P. Williams, H.G. Nelson. Gaseous hydrogen-induced cracking of Ti-5Al2.5Sn. Metall. Trans., 3 (1972) 2107-2113.

[46] M.J. Donachie (Jr). Titanium: A technical guide. second ed., ASM International, 2000.

[47] M. Garfinkle. An electrochemical model for hot-salt stress-corrosion of titanium alloys. NASA TN D-6779, 1972.

[48] D. Sinigaglia, G. Taccani, B. Vicentini. Hot-salt-stress-corrosion cracking of titanium alloys. Corros. Sci., 18 (1978) 781-796.

[49] R.S. Ondrejcin, M.R. Louthan Jr. Role of hydrogen chloride in hot-salt stress corrosion cracking of titanium-aluminium alloys. NASA CR-1133, 1968.

[50] G.J. Heimerl, D.N. Braski, D.M. Royster, H.B. Dexter. Salt stress corrosion of Ti-8Al-1Mo-1V alloy sheet at elevated temperatures. Stress Corrosion Cracking of Titanium: ASTM Special Technical Publication, 397 (1966) 194-214.

[51] R.L. Ashbrook. A survey of salt deposits in compressors of flight gas turbine engines. NASA TN D-50000, 1969.

[52] H.R. Gray. Hot-salt stress-corrosion of titanium alloys: Generation of hydrogen and its embrittling effect. NASA TN D-5000, 1969.

[53] R.S. Ondrejcin. The role of hydrogen in hot-salt stress corrosion cracking of titanium-aluminium alloys. NASA CR-1915, 1971.

[54] R.L. Kirchner, E.J. Ripling. The diffusion of corrosion products in hotsalt stress-corrosion cracking of titanium. Stress Corrosion Cracking of Titanium: ASTM Special Technical Publication, 397 (1966) 230-245. 


\section{List of Tables}

1 TEM-EDX composition data for the blue spot (1-4) as compared to the metallic substrate (5-6). Average uncertainty (at.\%) given to one significant figure. . . . . . . . . . . . . . .

2 SEM-EDX composition data from the machined specimen gauge surface beneath the blue spot. The positions of the acquired data are illustrated in Figure 11, with the average uncertainty (at. \%) given to one significant figure. Acquired using a $10 \mathrm{keV}$

electron-beam energy. . . . . . . . . . . . . . . . . . 


\begin{tabular}{|c|c|c|c|c|c|c|c|}
\hline & \multicolumn{7}{|c|}{ Composition (at.\%) } \\
\hline & $\mathrm{Ti}$ & $\mathrm{Al}$ & Sn & $\mathrm{Zr}$ & Mo & $\mathrm{O}$ & $\mathrm{Cl}$ \\
\hline 1 & 26 & 2.8 & 0.1 & 0.5 & 0.1 & 70 & 0.6 \\
\hline 2 & 24 & 4.2 & 0.7 & 0.9 & 3.0 & 66 & 1.2 \\
\hline 3 & 32 & 5.2 & 0.4 & 1.0 & 0.1 & 61 & 0.7 \\
\hline 4 & 32 & 2.4 & 0.1 & 1.0 & 0.4 & 63 & 0.8 \\
\hline$\overline{5}$ & $8 \overline{1}$ & $\overline{14}$ & 0.9 & 2.2 & 0.4 & $\overline{1} . \overline{8}$ & $\overline{0}$ \\
\hline 6 & 82 & 13 & 0.9 & 2.4 & 0.4 & 1.2 & 0 \\
\hline & \pm 2 & \pm 0.4 & \pm 0.1 & \pm 0.2 & \pm 0.2 & \pm 3 & \pm 0.1 \\
\hline
\end{tabular}

Table 1: TEM-EDX composition data for the blue spot (1-4) as compared to the metallic substrate (5-6). Average uncertainty (at.\%) given to one significant figure. 


\begin{tabular}{cccccc:ccc} 
& \multicolumn{10}{c}{ Composition (at.\%) } \\
\cline { 2 - 9 } & $\mathrm{Ti}$ & $\mathrm{Al}$ & $\mathrm{Sn}$ & $\mathrm{Zr}$ & $\mathrm{Mo}$ & $\mathrm{O}$ & $\mathrm{Cl}$ & $\mathrm{Na}$ \\
\hline 1 & 26 & 3.8 & 0.3 & 0.7 & 0.9 & 67 & 0.6 & 0.4 \\
2 & 25 & 3.6 & 0.2 & 0.6 & 0.5 & 69 & 0.5 & 0.3 \\
3 & 26 & 3.4 & 0.3 & 0.7 & 1.3 & 66 & 1.1 & 0.4 \\
\hdashline 4 & $\overline{48}$ & $\overline{6} . \overline{0}$ & 0.5 & 1.6 & $\overline{3} . \overline{0}$ & $\overline{41}$ & 0 & 0.1 \\
5 & 47 & 5.4 & 0.6 & 1.5 & 3.9 & 42 & 0 & 0 \\
6 & 48 & 6.6 & 0.6 & 1.4 & 0.7 & 43 & 0 & 0.1 \\
\hline \pm & 0.4 & 0.07 & 0.03 & 0.04 & 0.05 & 0.7 & 0.03 & 0.04
\end{tabular}

Table 2: SEM-EDX composition data from the machined specimen gauge surface beneath the blue spot. The positions of the acquired data are illustrated in Figure 11, with the average uncertainty (at. \%) given to one significant figure. Acquired using a $10 \mathrm{keV}$ electron-beam energy. 


\section{List of Figures}

1 Micrographs demonstrating the microstructure of the material studied. (LOM) Light optical microscopy overview; (BC) Band contrast formed image from electron backscatter diffraction; $(\alpha / \beta$ IPF). Alpha and beta phase inverse pole figure (IPF) colour images, coloured parallel to the loading direction-indexed at $76 \%$; (BSEI) Backscatter electron images demonstrating the fine secondary alpha laths residing within the beta matrix. . . . . . . 27

2 Schematic illustration of FIB-SIMS set-up: (1) Blue spot; (2) adjacent surface feature; (3) set 2 data; (4) set 1 data; (5) mass spectrum 0-200 AMU; (6) depth profile trenches, similar to trenches in sets 1 and $2 \ldots \ldots \ldots \ldots \ldots \ldots \ldots$

3 Light optical micrograph (LOM) and secondary electron image (SEI) demonstrating the semi-elliptical morphology and the uneven boundary of the blue spot on the fracture surface. . . . . . . 29

4 Secondary electron images taken from areas within the discoloured fatigue crack origin: (a) and (b) distinctive fractographic boundary coinciding with the blue discolouration, (c) and (d) evidence of underlying microstructure on the fracture surface, (e) and (f) build up of corrosion product on the fracture surface. . . . . . . 30

5 Secondary electron images exhibiting features observed across the fatigue fracture surface (outside the blue spot); $a$ corresponds to crack length. Top row - x5k magnification, bottom row - x20k magnification; from left to right increasing $\Delta \mathrm{K}$, (a) structure sensitive growth accompanied by facetting, (b) adjacent facets and (torn) striations, c(i) distribution of secondary cracks and fine striations parallel to the secondary cracks c(ii), (d) ductile microvoids. Crack growth directions are shown by the arrows. . . . 31

6 Qualitative long-exposure SEM-EDX maps from the fatigue crack origin. (LOM) Demonstrating the semi-elliptical morphology of the "blue spot"; (O) Significant oxygen enhancement and (Ti) Titanium reduction within the blue spot region; $(\mathrm{Cl})$ Tentative visual evidence of the local presence of $\mathrm{Cl}$ in the blue spot region. 32

7 (a) Overview of TEM foil showing the microstructure underlying the blue spot; (b) The blue spot layer observed at higher magnification (dotted lines). EDX spectra data from the blue spot (1-4) and subsurface primary alpha laths (5-6) are given in Table 1. 33

8 (Top) High magnification STEM-EDX chemical maps taken from a region encompassing the platinum protected fracture surface, the supposed blue spot and base metal matrix. An overview of the sample is shown in Figure 7(a). Top right micrograph illustrates the area from which the maps were measured. Camera length $15 \mathrm{~cm}$, spot size $1.5 \mathrm{~nm}$. (Bottom) X-ray spectra from locations within the platinum layer (circle) compared to within the oxide layer (square), demonstrates overlapping peaks for $\mathrm{Pt}$ and $\mathrm{Cl}$. . . 34 
$9 \quad$ Secondary electron images of the blue spot and underlying surface feature: (a) $30^{\circ}$ stage tilt with the fracture surface $\sim 60^{\circ}$ to the electron beam; (b) specimen gauge surface normal to the electron beam. . . . . . . . . . . . . . . 35

10 Light interferometry on the surface defect shown on the gauge section in Figure 9: False colour surface maps (upper) and surface profiles (lower) of the defect on the machined gauge surface of the specimen. (Left) data as measured; (Right) measured after application of high pass fixed FFT filter selecting frequency information $>50 \mathrm{~mm}^{-1}$ to emphasise roughness data. . . . . . 36

11 Qualitative SEM-EDX mapping of the defect on the machined gauge surface of the specimen: (SEI) includes the positions of spectra as given in Table 2 - spectra 1-3 defect, spectra 4-6 machined surface. . . . . . . . . . . . . . . 37

12 FIB-SIMS data: (a) SEI at $0^{\circ}$ tilt before FIB sputter clean; (b) SEI at $30^{\circ}$ tilt after $20 \mathrm{nA}$ sputter clean and depth profiling at $3 \mathrm{nA}$; (c) ${ }^{16} \mathrm{O}^{-}$and ${ }^{35} \mathrm{Cl}^{-}$profiles; (d) ${ }^{23} \mathrm{Na}^{+} /{ }^{16} \mathrm{O}^{-}$and ${ }^{35} \mathrm{Cl}^{-}$ profiles. . . . . . . . . . . . . . . . . . . 38

13 Proposed HSSCC mechanism: (a) NaCl deposition; (b) HSSCC crack nucleation; (c) volatile $\mathrm{TiCl}_{4}$ reacts with water molecules or oxygen to form $\mathrm{TiO}_{2}$ at the crack mouth; (d) blue spot formation - $\mathrm{TiO}_{2}$ overlaid on and mixed with titanium chlorides. . . . . . . 39 

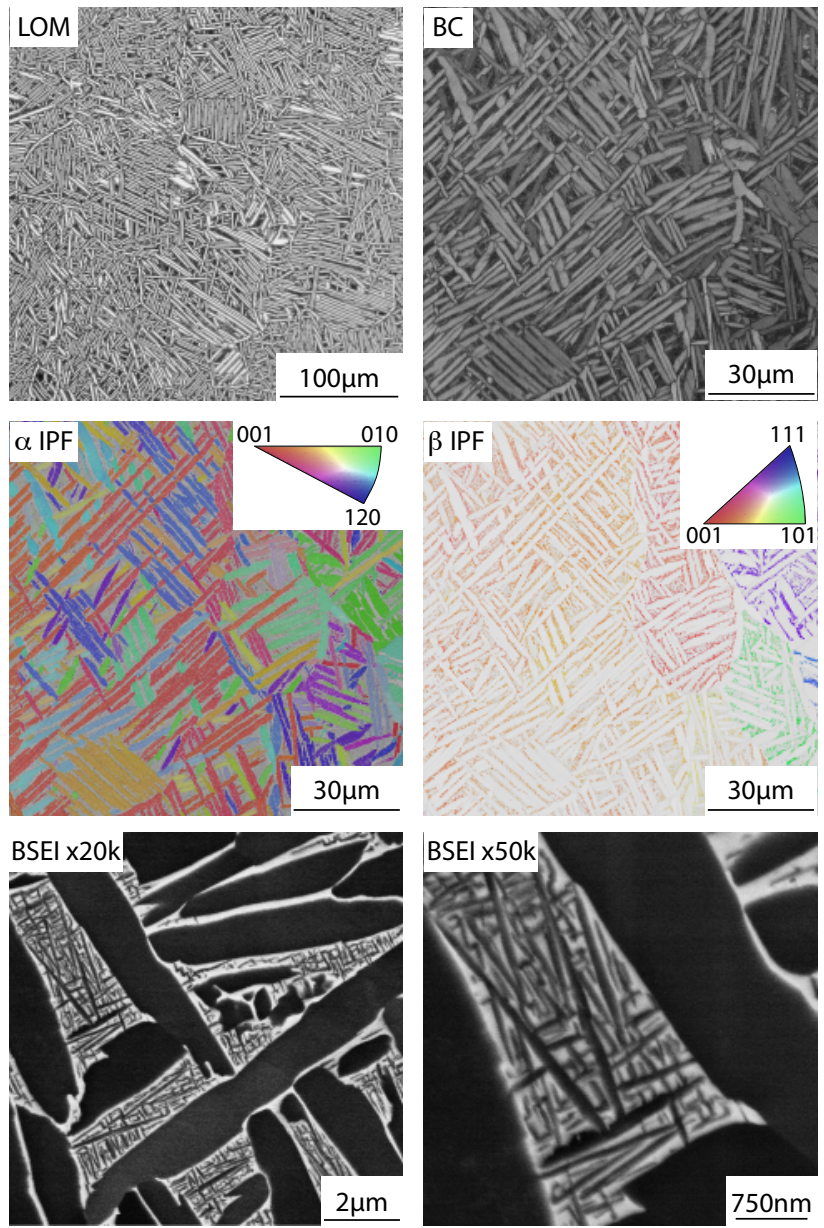

Figure 1: Micrographs demonstrating the microstructure of the material studied. (LOM) Light optical microscopy overview; (BC) Band contrast formed image from electron backscatter diffraction; $(\alpha / \beta$ IPF). Alpha and beta phase inverse pole figure (IPF) colour images, coloured parallel to the loading direction-indexed at 76\%; (BSEI) Backscatter electron images demonstrating the fine secondary alpha laths residing within the beta matrix. 


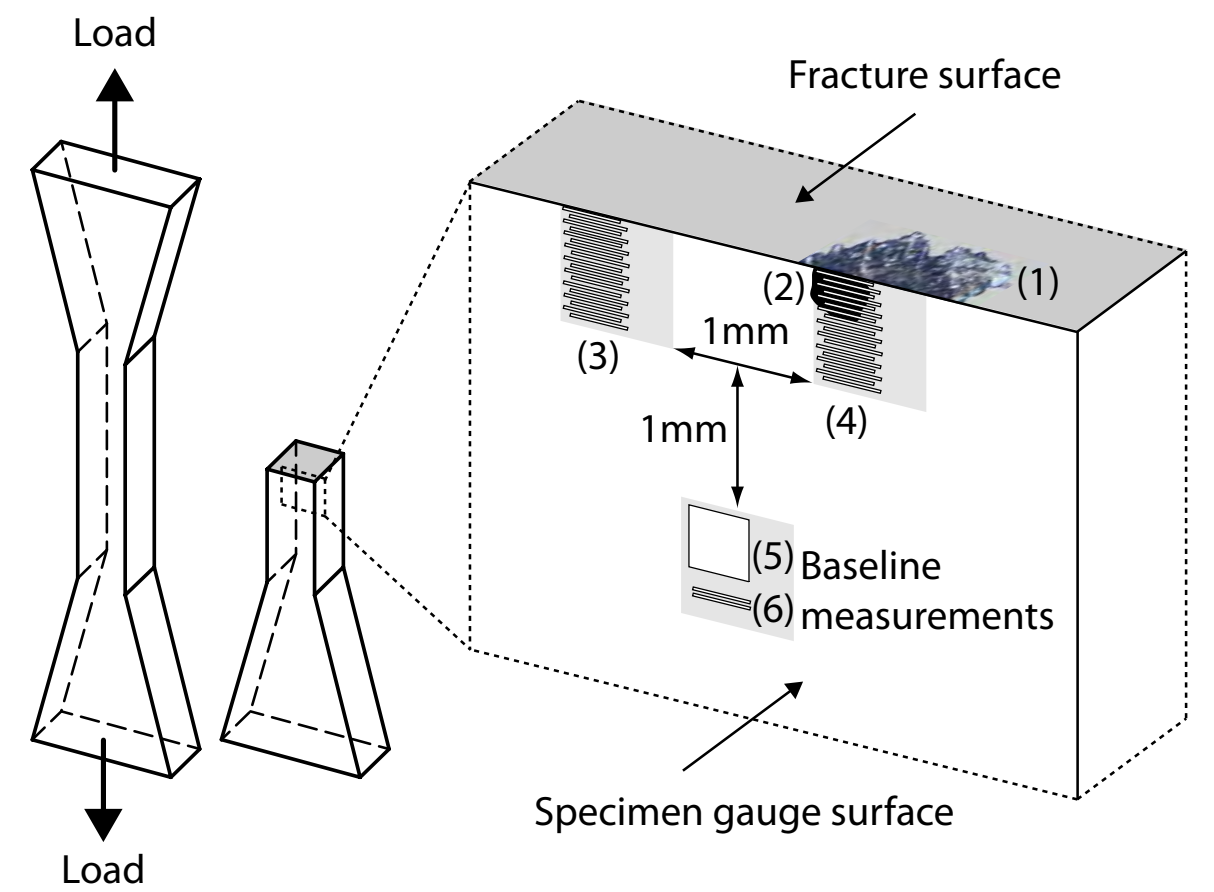

Figure 2: Schematic illustration of FIB-SIMS set-up: (1) Blue spot; (2) adjacent surface feature; (3) set 2 data; (4) set 1 data; (5) mass spectrum 0-200 AMU; (6) depth profile trenches, similar to trenches in sets 1 and 2 . 

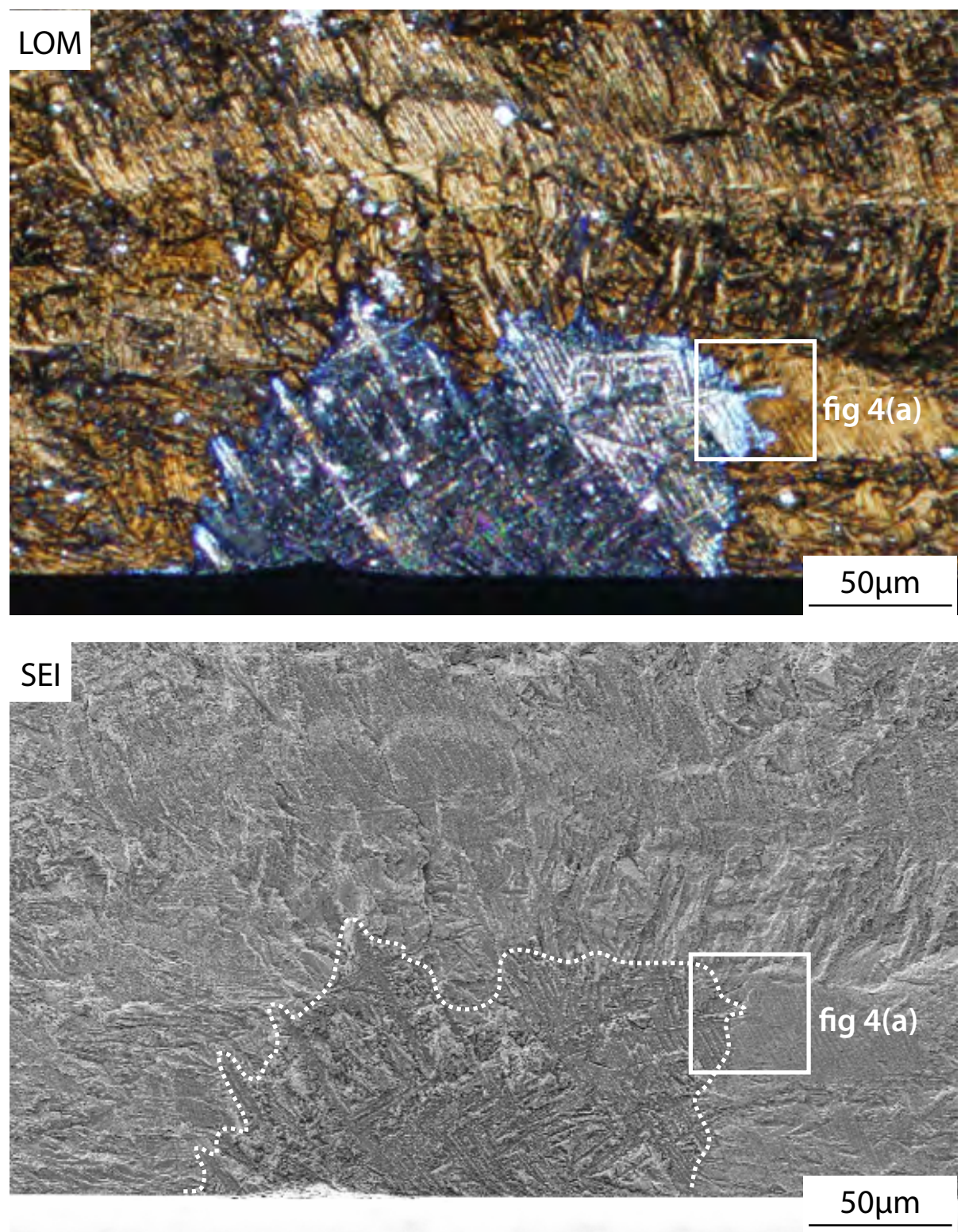

Figure 3: Light optical micrograph (LOM) and secondary electron image (SEI) demonstrating the semi-elliptical morphology and the uneven boundary of the blue spot on the fracture surface. 

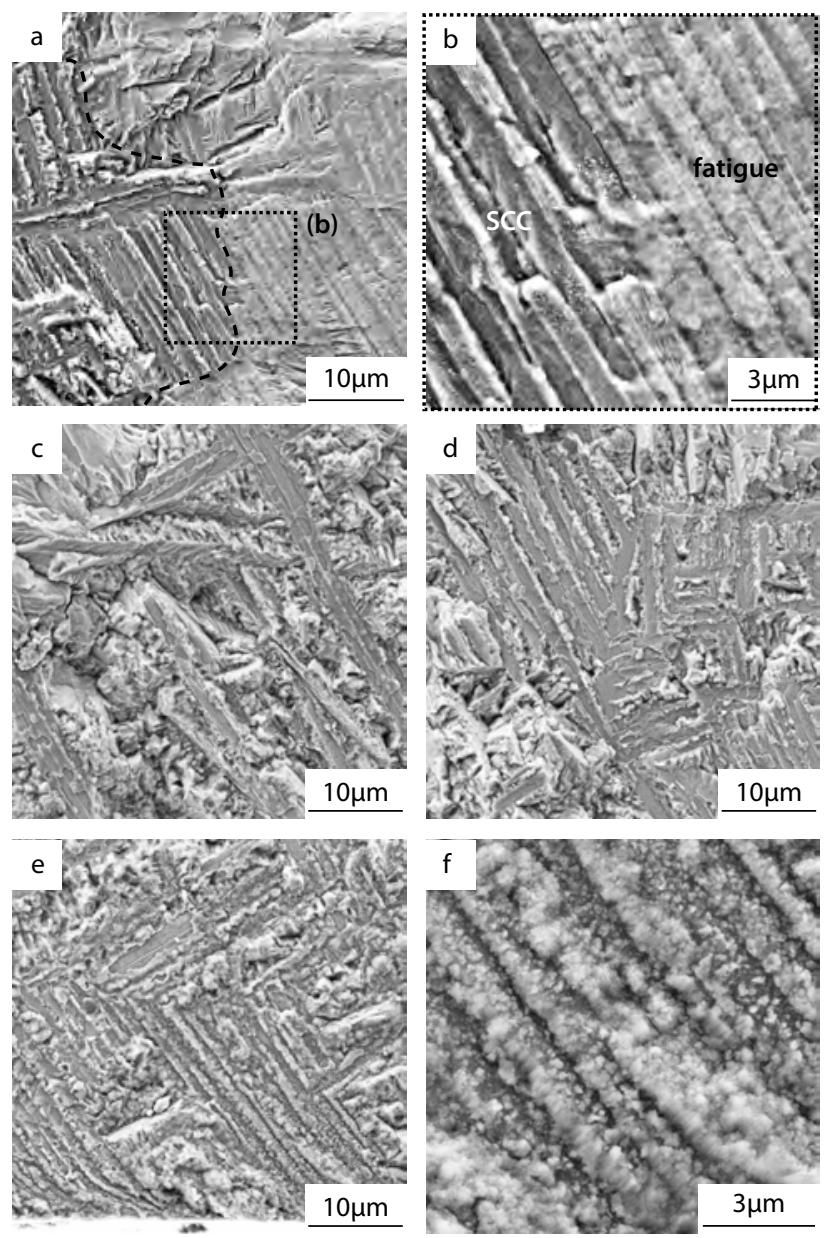

Figure 4: Secondary electron images taken from areas within the discoloured fatigue crack origin: (a) and (b) distinctive fractographic boundary coinciding with the blue discolouration, (c) and (d) evidence of underlying microstructure on the fracture surface, (e) and (f) build up of corrosion product on the fracture surface. 

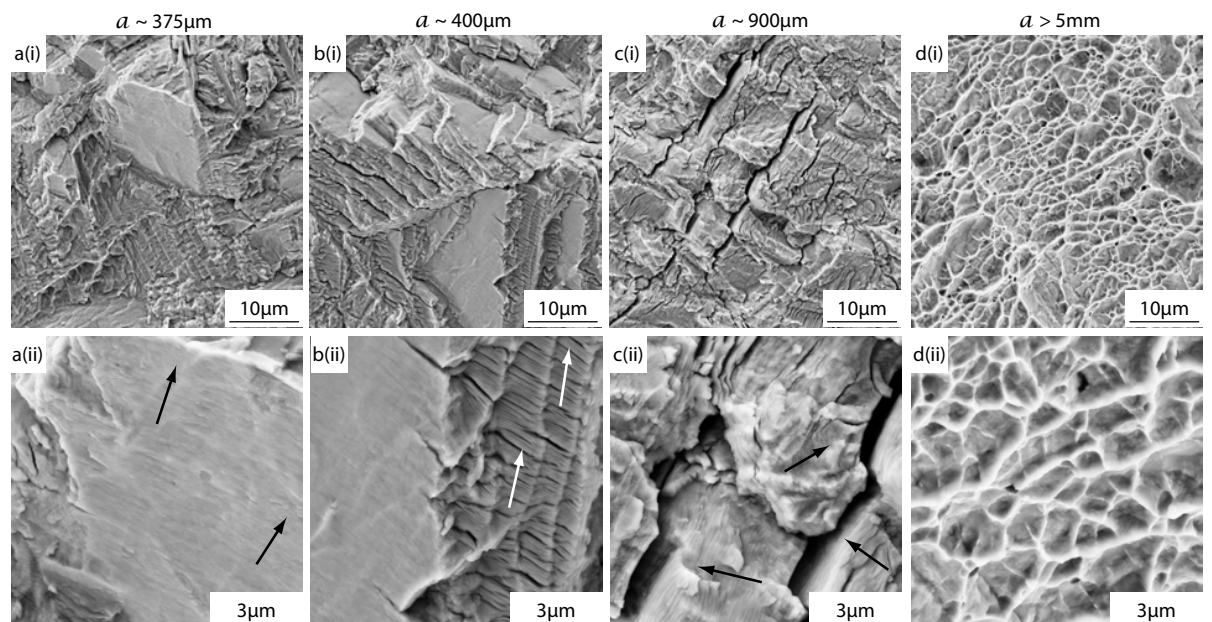

Figure 5: Secondary electron images exhibiting features observed across the fatigue fracture surface (outside the blue spot); $a$ corresponds to crack length. Top row - x5k magnification, bottom row - x20k magnification; from left to right increasing $\Delta K$, (a) structure sensitive growth accompanied by facetting, (b) adjacent facets and (torn) striations, c(i) distribution of secondary cracks and fine striations parallel to the secondary cracks c(ii), (d) ductile microvoids. Crack growth directions are shown by the arrows. 

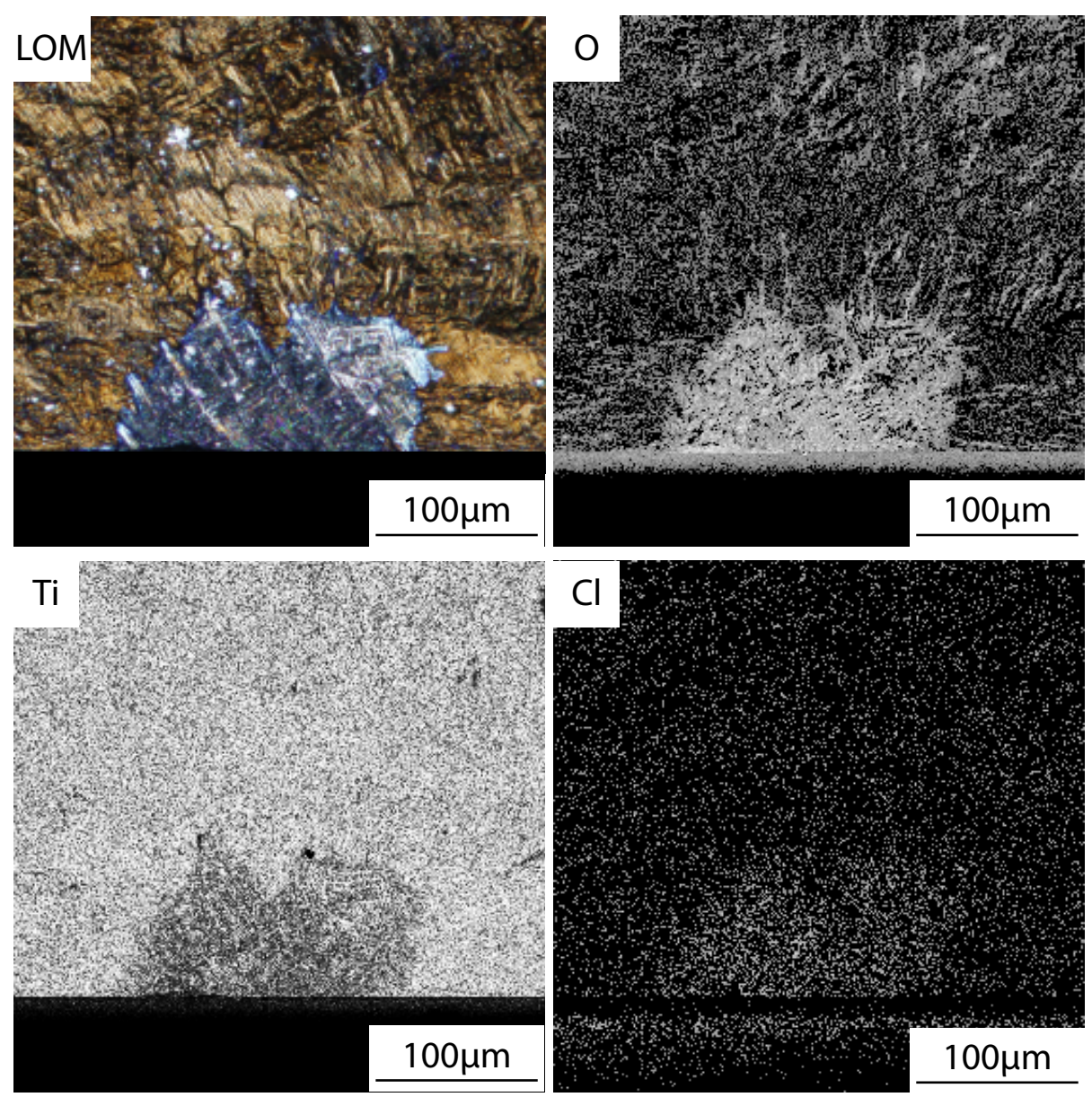

Figure 6: Qualitative long-exposure SEM-EDX maps from the fatigue crack origin. (LOM) Demonstrating the semi-elliptical morphology of the "blue spot"; (O) Significant oxygen enhancement and (Ti) Titanium reduction within the blue spot region; (Cl) Tentative visual evidence of the local presence of $\mathrm{Cl}$ in the blue spot region. 

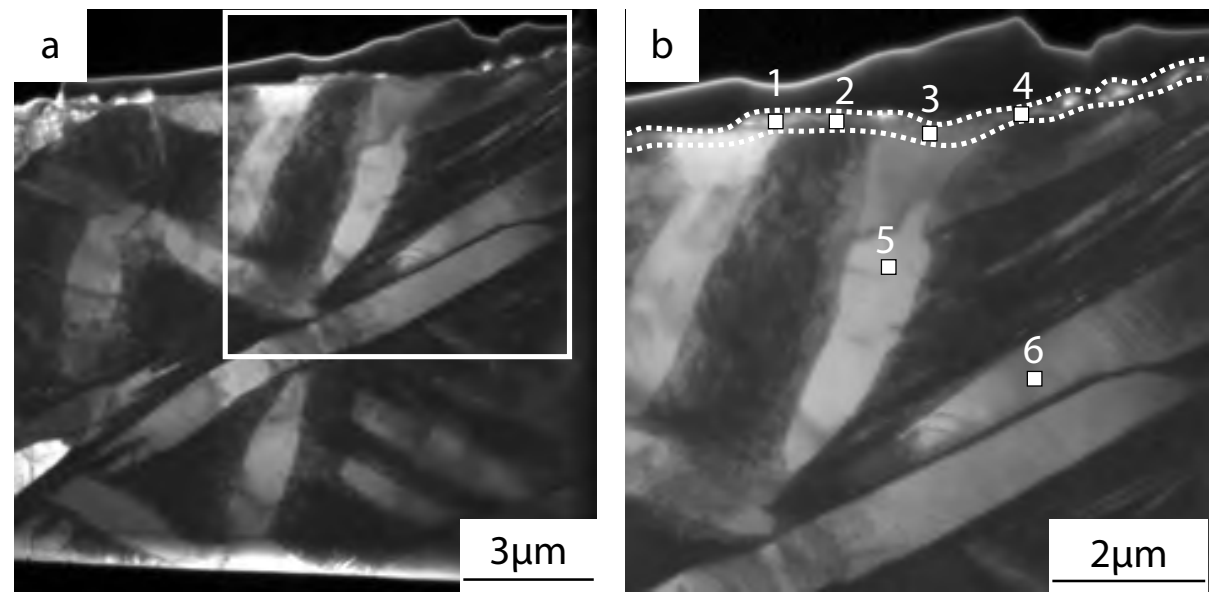

Figure 7: (a) Overview of TEM foil showing the microstructure underlying the blue spot; (b) The blue spot layer observed at higher magnification (dotted lines). EDX spectra data from the blue spot (1-4) and subsurface primary alpha laths (5-6) are given in Table 1. 

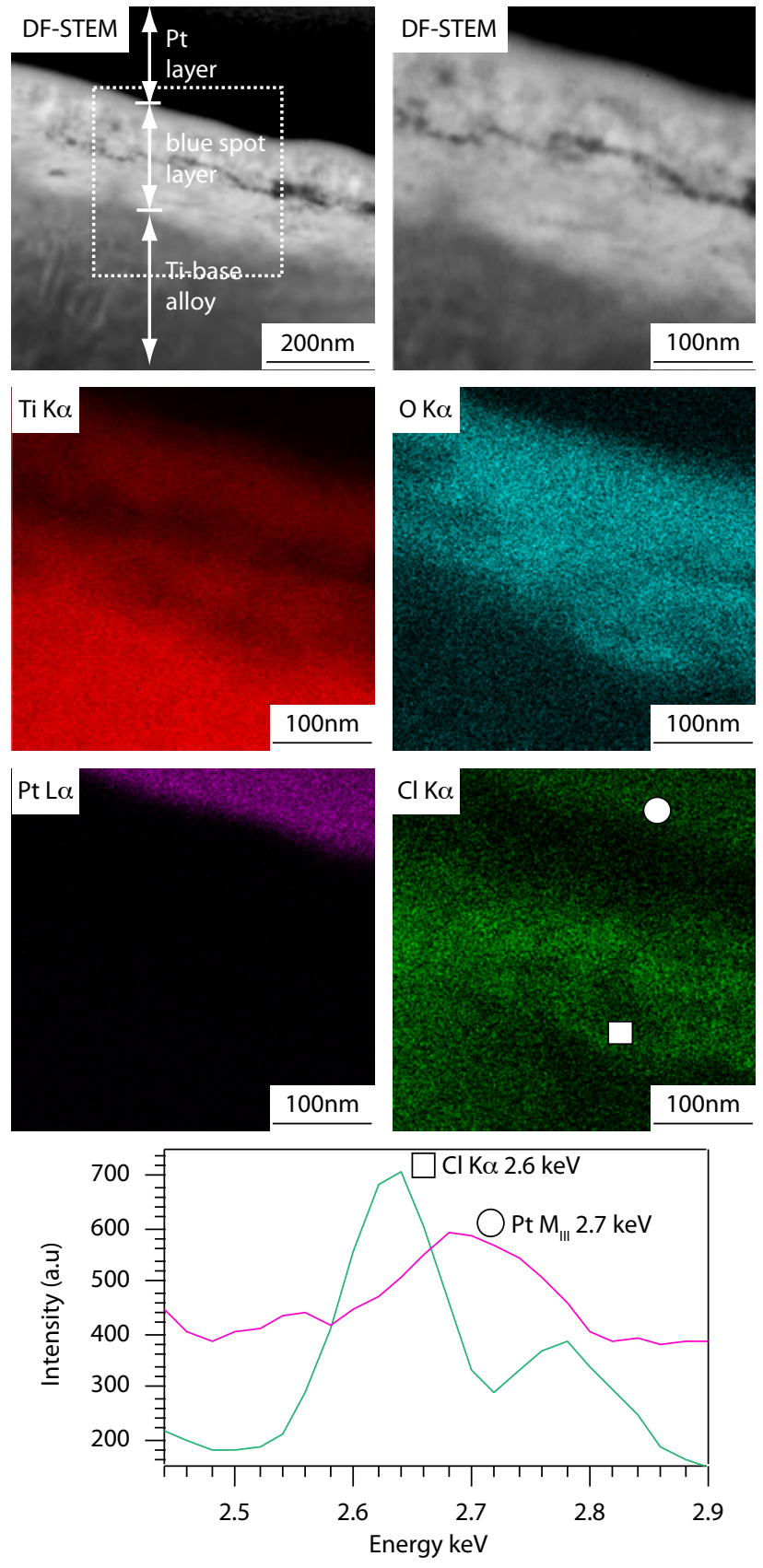

Figure 8: (Top) High magnification STEM-EDX chemical maps taken from a region encompassing the platinum protected fracture surface, the supposed blue spot and base metal matrix. An overview of the sample is shown in Figure 7(a). Top right micrograph illustrates the area from which the maps were measured. Camera length $15 \mathrm{~cm}$, spot size $1.5 \mathrm{~nm}$. (Bottom) X-ray spectra from locations within the platinum layer (circle) compared to within the oxide layer (square), demonstrates overlapping peaks for $\mathrm{Pt}$ and $\mathrm{Cl}$. 

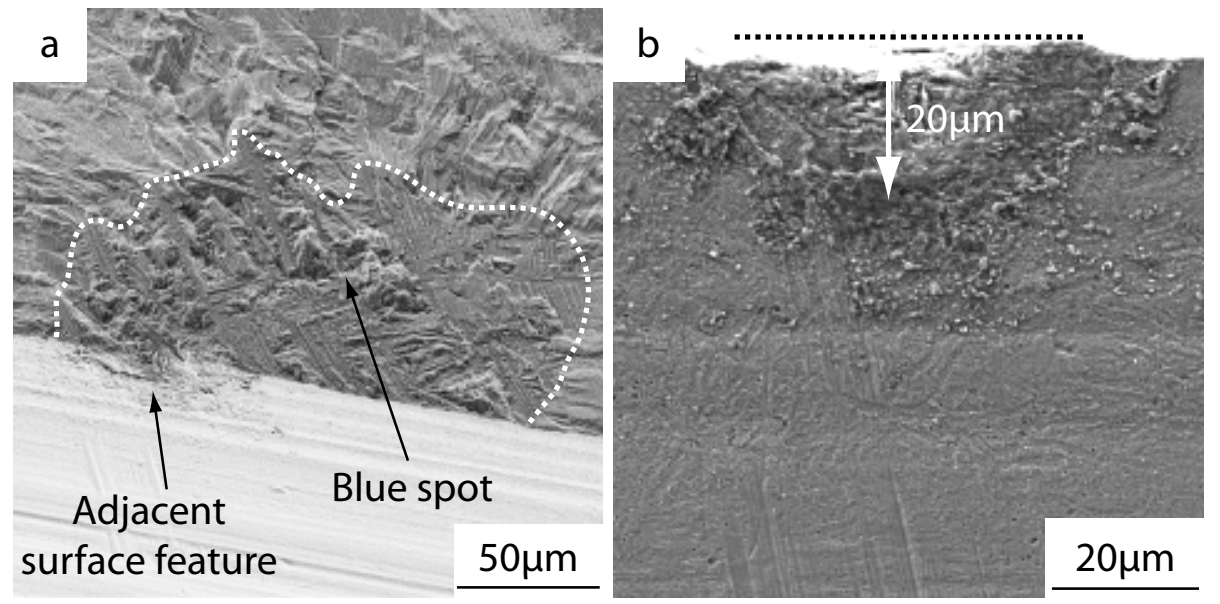

Figure 9: Secondary electron images of the blue spot and underlying surface feature: (a) $30^{\circ}$ stage tilt with the fracture surface $\sim 60^{\circ}$ to the electron beam; (b) specimen gauge surface normal to the electron beam. 

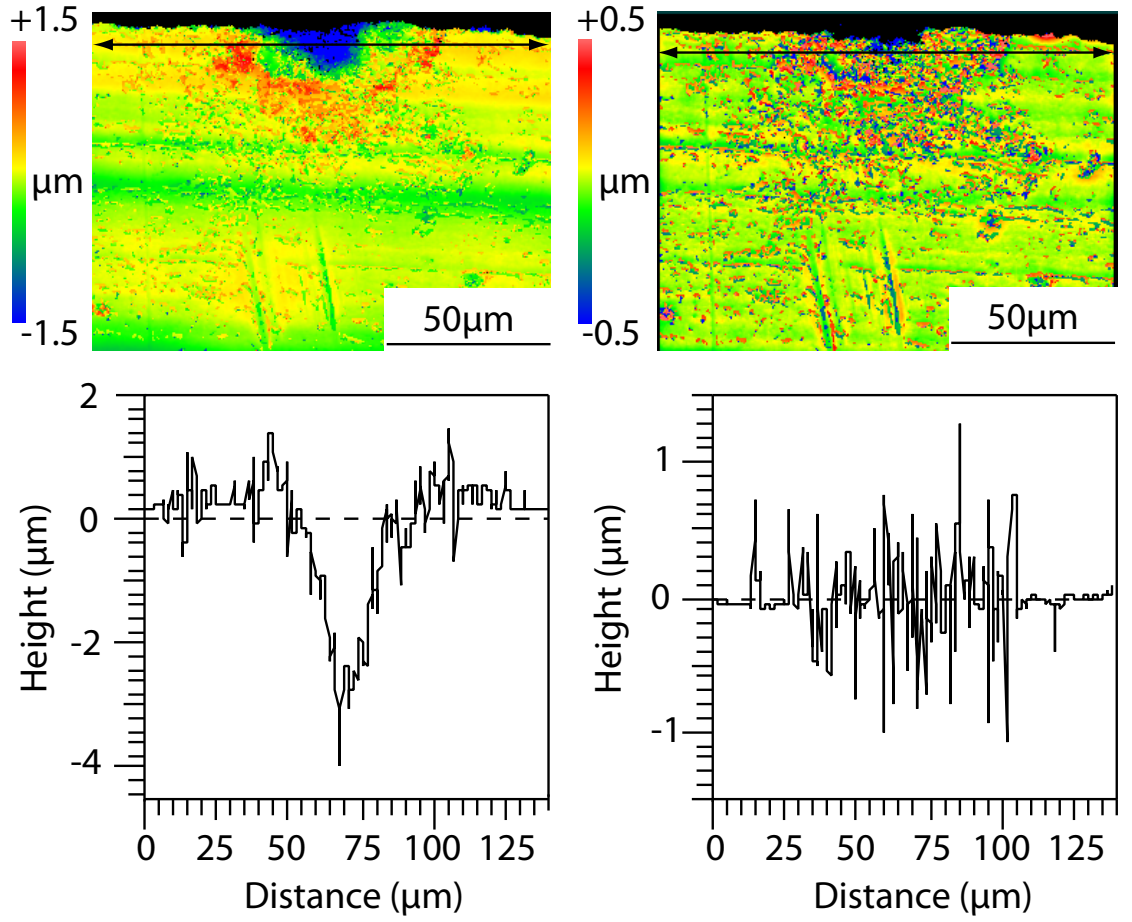

Figure 10: Light interferometry on the surface defect shown on the gauge section in Figure 9: False colour surface maps (upper) and surface profiles (lower) of the defect on the machined gauge surface of the specimen. (Left) data as measured; (Right) measured after application of high pass fixed FFT filter selecting frequency information $>50 \mathrm{~mm}^{-1}$ to emphasise roughness data. 

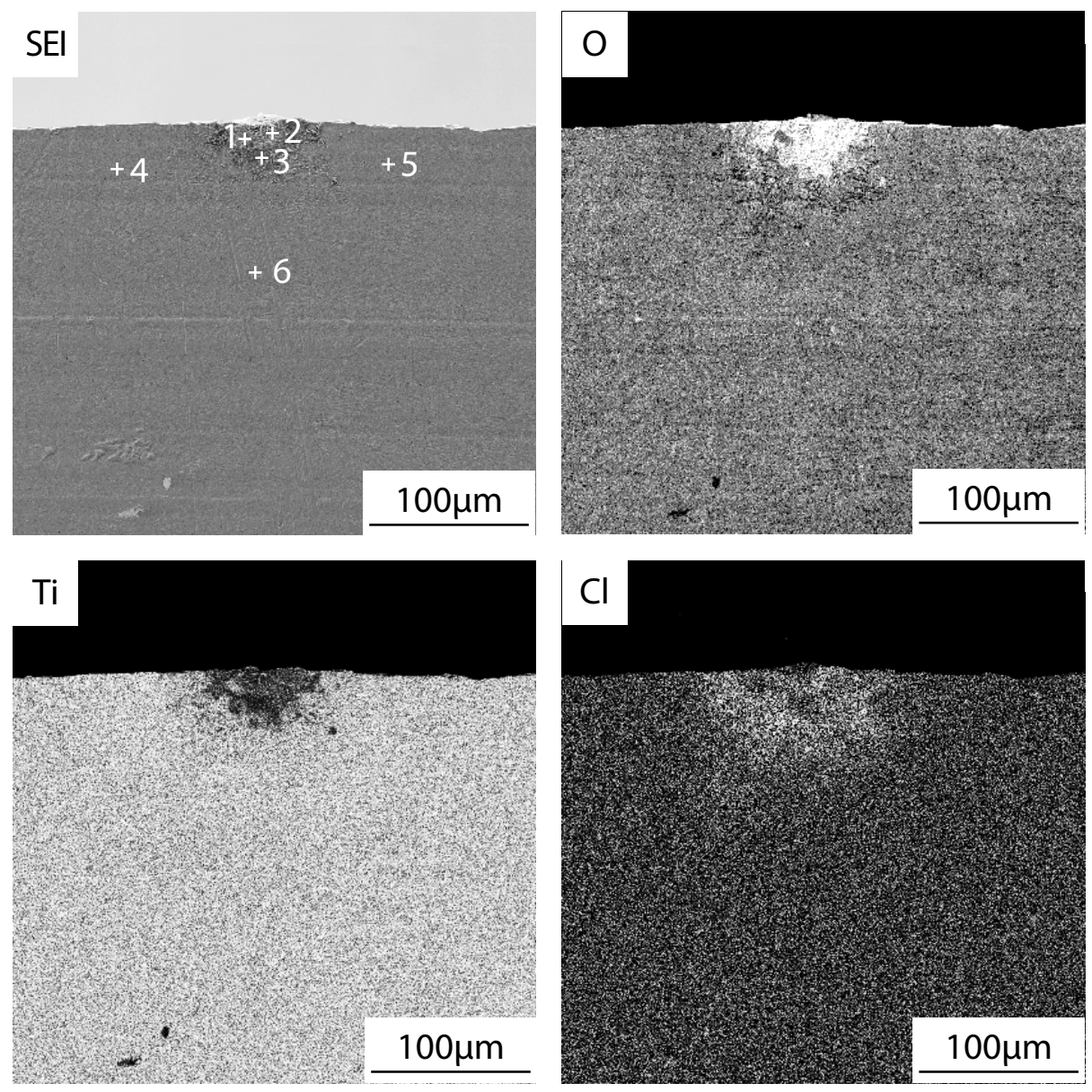

Figure 11: Qualitative SEM-EDX mapping of the defect on the machined gauge surface of the specimen: (SEI) includes the positions of spectra as given in Table 2 - spectra 1-3 defect, spectra 4-6 machined surface. 


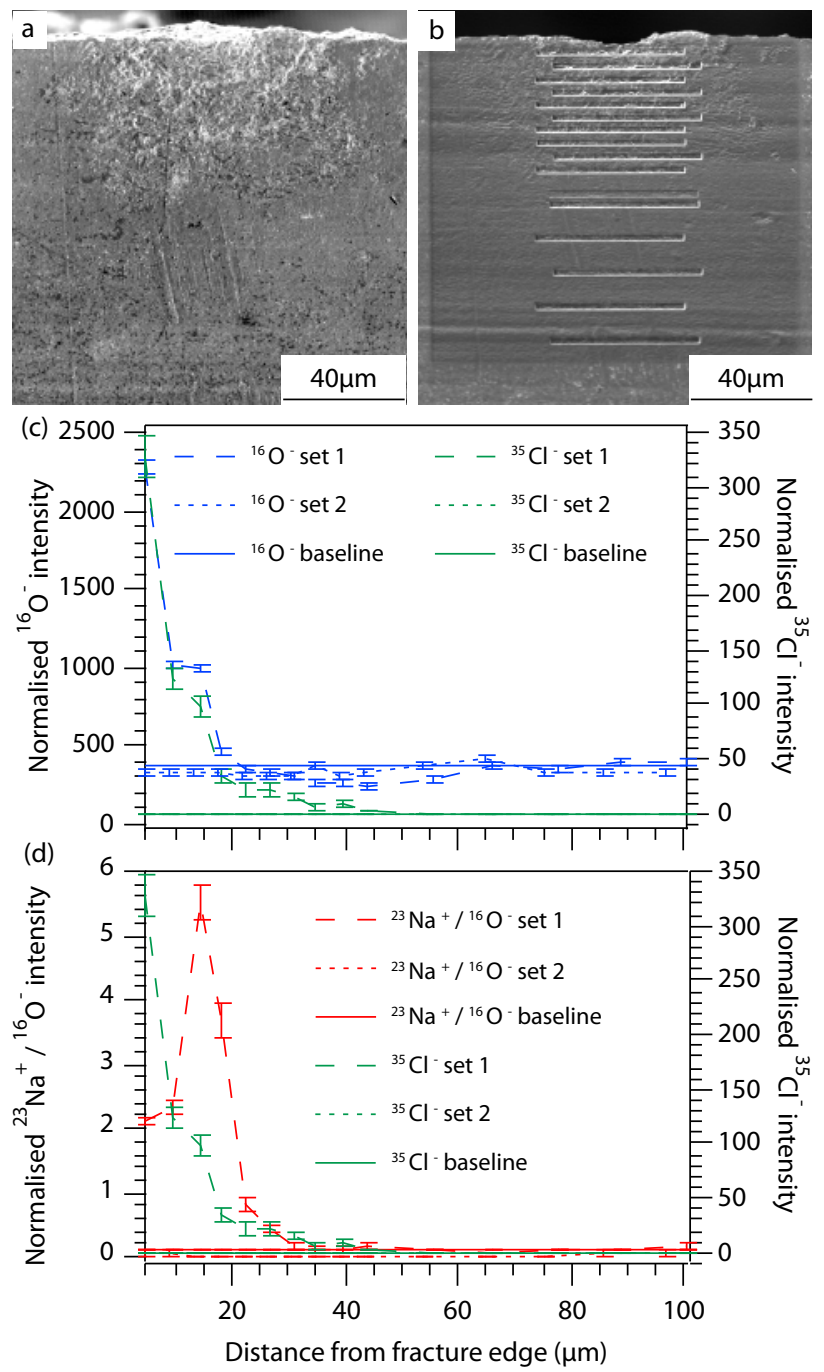

Figure 12: FIB-SIMS data: (a) SEI at $0^{\circ}$ tilt before FIB sputter clean; (b) SEI at $30^{\circ}$ tilt after $20 \mathrm{nA}$ sputter clean and depth profiling at $3 \mathrm{nA} ;(\mathrm{c}){ }^{16} \mathrm{O}^{-}$and ${ }^{35} \mathrm{Cl}^{-}$profiles; $(\mathrm{d})^{23} \mathrm{Na}^{+} /{ }^{16} \mathrm{O}^{-}$ and ${ }^{35} \mathrm{Cl}^{-}$profiles. 


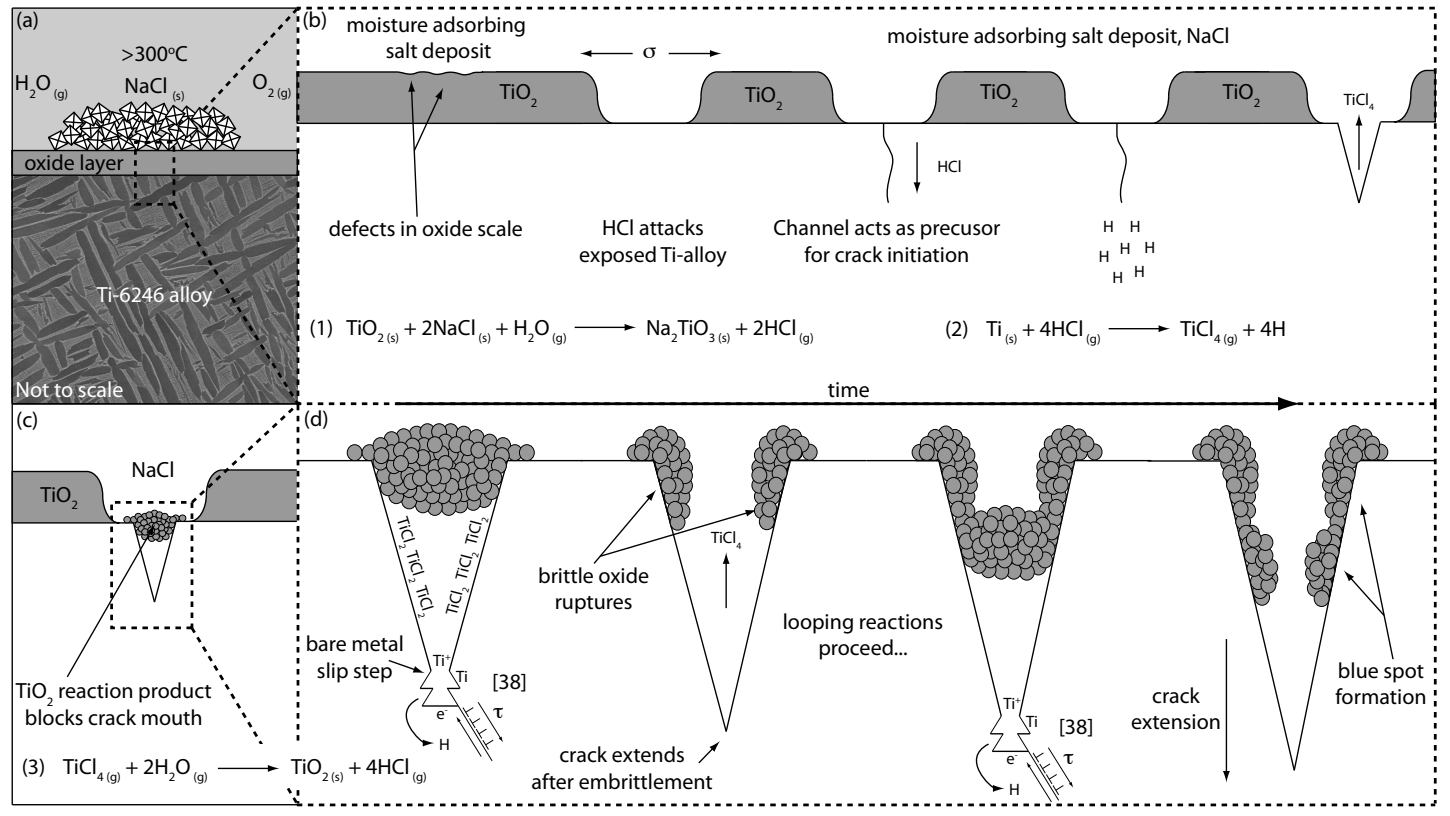

Figure 13: Proposed HSSCC mechanism: (a) NaCl deposition; (b) HSSCC crack nucleation; (c) volatile $\mathrm{TiCl}_{4}$ reacts with water molecules or oxygen to form $\mathrm{TiO}_{2}$ at the crack mouth; (d) blue spot formation - $\mathrm{TiO}_{2}$ overlaid on and mixed with titanium chlorides. 